\title{
Early Industrial Roots of Green Chemistry and the history of the BHC Ibuprofen process invention and its Quality connection
}

\author{
Mark A. Murphy ${ }^{1}$
}

Published online: 25 October 2017

(C) The Author(s) 2017. This article is an open access publication

\begin{abstract}
Conventional wisdom and many published histories of "Green Chemistry" describe its start as being a result of governmental and/or regulatory actions at the US Environmental Protection Agency ("EPA") during the early 1990's. But there were many Real World industrial examples of environmentally friendly commercial processes in the oil and commodity chemicals industries for decades prior to the 1990s. Some early examples of commercial "Green Chemistry" are briefly described in this article. The Boots/Hoechst Celanese ("BHC") Ibuprofen process was one of the earliest multiple-award-winning examples of industrial "Green Chemistry" in the fine chemical/pharmaceutical industry. The author, who conceived the BHC Ibuprofen synthetic strategy in 1984, reveals and documents that the BHC Ibuprofen process was not primarily a result of governmental or regulatory mandates, or environmentalist or political motivations. The BHC ibuprofen process, and probably many other early industrial "green" inventions, evolved from, and their development and commercialization motivated and guided by, a long prior industrial culture of both scientific and technical evolution. The invention and commercialization of these early industrial commercialized processes, and the BHC Ibuprofen process were also guided by both competitive and economic market needs, personal human motivations, and a low waste culture of "Quality" and "Continuous Improvement" that the commodity chemical industry internally promoted in the 1980's. The author comments on some perceptions of the status of Green Chemistry now, and directions it should consider going in the future. The author recommends that young Green Chemists and/or Green Engineers reconsider "Quality" approaches in order to genuinely lead Society toward a Greener future.
\end{abstract}

Keywords History · Green Chemistry · Green engineering · Leadership · EPA · Ibuprofen · W. Edwards Deming · Quality · Presidential Green Chemistry Award

Mark A. Murphy

uvlawpatents@gmail.com

1 UVLAW Patents LLC, 1015 E. College St., Griffin, GA 30224, USA 


\section{The origins of Green Chemistry?}

According to the U.S. EPA's website in 2012, "'Green chemistry consists of chemicals and chemical processes designed to reduce or eliminate negative environmental impacts. The use and production of these chemicals may involve reduced waste products, non-toxic components, and improved efficiency. Green chemistry is a highly effective approach to pollution prevention because it applies innovative scientific solutions to real-world environmental situations."

Conventional wisdom and histories of Green Chemistry (see Linthorst 2010; Anastas and Beach 2009, and others) typically describe the origins of Green Chemistry as arising in the early 1990s, from concepts and actions at the US Government and Environmental Protection Agency (EPA), ${ }^{2}$ and/or from the academic world. Green Chemistry (and Engineering) has subsequently blossomed into entirely new fields of research, with multitudes of specialized journals and conferences devoted to the new field, all over the world (see Fig. 1 of Anastas and Beach 2009). However, Professor Martyn Poliakoff recently noted that "Although most people agree that the EPA gave birth to green chemistry, there is much less certainty about its conception" (Poliakoff 2013).

This author originally conceived, in 1984, one of the most widely recognized early industrial examples of Green Chemistry, the BHC Ibuprofen process. The technical details of the BHC ibuprofen process were first published in patent form in 1988, and the process was commercialized in 1992. This article will identify and describe some of the broad and intertwined technical and human/cultural actions, roots and motivations that preceded and contributed to the conception and evolution, development, and commercialization of the BHC ibuprofen process, and likely contributed to many other early examples of industrial "Green Chemistry" that were in actual commercial practice long before the 1990s.

\section{Conventional histories of Green Chemistry}

According to many conventional histories (see for example Linthorst 2010, and Anastas and Beach 2009, p. 3), "Green Chemistry" was first defined and publicized during the early 1990 ' ${ }^{3}$ by the US government and EPA, and/or by the academic world. In another example, according to the EPA website in $2012,{ }^{4}$

The Pollution Prevention Act of 1990 established a national policy to prevent or reduce pollution at its source whenever feasible, and provided an opportunity to expand beyond traditional EPA programs and devise creative strategies to protect

\footnotetext{
1 The quotation was accessed on the EPA website, http://www.epa.gov/greenchemistry/pubs/about gc.html in 2012, but is no longer available there. Very similar passages are still recited at multiple other locations, including the National Service Center for Environmental Publications at http://nepis.epa.gov/Exe/ZyNET.exe/P1004H5E. TXT?ZyActionD=ZyDocument $\&$ Client=EPA\&Index $=2000+$ Thru $+2005 \&$ Docs $=\& Q u e r y=\&$ Time $=\&$ EndTime $=\&$ SearchMethod $=1 \&$ TocRestrict $=$ n $\&$ Toc $=\&$ TocEntry $=\& Q$ Field $=\& Q$ FieldYear $=\& Q$ FieldMonth $=\& Q$ FieldDay $=\&$ IntQFieldOp=0\&ExtQFieldOp=0\&XmlQuery $=\&$ File $=\mathrm{D} \% 3 \mathrm{~A} \% 5 \mathrm{Czy}$ files $\% 5 \mathrm{CIndex} \% 20 \mathrm{Data} \% 5 \mathrm{C} 00$ thru $05 \%$ 5CTxt\%5C00000020\%5CP1004H5E.txt\&User=ANONYMOUS\&Password=anonymous\&SortMethod= h\%7C\&MaximumDocuments=1\&FuzzyDegree=0\&ImageQuality=r75g8/r75g8/x150y150g16/i425\&Di splay $=\mathrm{p} \%$ 7Cf $\&$ DefSeekPage $=\mathrm{x} \&$ SearchBack $=$ ZyActionL $\&$ Back $=$ ZyActionS $\&$ BackDesc $=$ Results $\% 20$ page \&MaximumPages $=1 \&$ ZyEntry $=1 \&$ SeekPage $=x \& Z y P U R L$.

2 The EPA was created in 1970, during the Nixon administration.

3 The 1990 Pollution Prevention Act was passed during the administration of George Herbert Walker Bush.

4 The quotation was accessed on the EPA website, http://www.epa.gov/greenchemistry/pubs/epa_gc.html, in 2012 .
} 
human health and the environment....Shortly after the passage of the Pollution Prevention Act of 1990, the Office of Pollution Prevention and Toxics (OPPT) explored the idea of developing new or improving existing chemical products and processes to make them less hazardous to human health and the environment. In 1991, OPPT launched a model research grants program called 'Alternative Synthetic Pathways for Pollution Prevention'. This program provided unprecedented grants for research projects that include pollution prevention in the design and synthesis of chemicals.

Further, according to the EPA, during the Clinton Administration, the EPA's OPPT program was expanded to other topics, such as greener solvents and safer chemicals, and was renamed "Green Chemistry." In 1995, as part of President Clinton's "Reinventing Environmental Regulations Initiatives," OPPT launched the "Presidential Green Chemistry Challenge," a voluntary collaboration between the EPA, academia, and industry, to support further green chemistry research and publicly recognize outstanding examples of green chemistry. The first Presidential Green Chemistry Awards were presented by the EPA in 1996, and are presented annually to this day. ${ }^{5}$ Paul T. Anastas, then of EPA and more recently of Princeton University, has been instrumental in promoting the Green Chemistry concepts and programs. ${ }^{6}$ In a 2012 Scientific American article, Anastas was described as "the father of Green Chemistry. ${ }^{7}$

Also, in 1991 Professor Barry M. Trost of Stanford University published an article in Science entitled "The Atom Economy- A Search for Synthetic Efficiency" (Trost 1991). ${ }^{8}$ Professor Trost briefly described a long history of scientific quests for other types of selectivity in the synthesis of complex organic molecules. Then Prof. Trost commented that

In the quest for selectivity, a second feature of efficiency is frequently overlooked how much of the reactants end up in the product, a feature we might refer to as atom economy.... An alternative process that is both selective and atom economical remains a challenge. The ideal reaction would incorporate all of the atoms of the reactants. Major benefits that derive from such processes include more effective use of limited raw materials and decreased emissions and waste disposal.

In 1998, Professor Trost was awarded a Presidential Green Chemistry Award, for "The Development of the Concept of Atom Economy." But the ACS/EPA's published commentary to Prof. Trost's Presidential Green Chemistry Award also noted ${ }^{9}$;

When Prof. Trost's first paper on atom economy appeared in the literature, the idea generally was not accepted by either academia or industry. Many in industry, however, were practicing this concept without enunciating it. (Bolding added) Others in industry did not consider the concept because it did not appear to have

\footnotetext{
5 Current information on the EPA/ACS Presidential Green Chemistry Challenge Awards is currently available at http://www.epa.gov/greenchemistry/information-about-presidential-green-chemistry-challenge.

${ }^{6}$ See for example Anastas and Warner (1998).

7 See https://www.scientificamerican.com/article/qa-paul-anastas-departing-epa-science-advisor/.

8 There are some indications in the literature that Professor Trost may have originally formulated the concept of "Atom Economy" as early as 1973.

9 This quote appeared in the original and Official announcement/brochure for the 1998 Presidential Green Chemistry Awards, which is no longer available, but also appears in the updated EPA description of Prof. Trost's award at http://www.epa.gov/greenchemistry/1998-academic-award-trost.
} 
economic consequence. Today, all of the chemical industry explicitly acknowledges the importance of atom economy.

Others have also hinted that a pre-1990s industrial practice of Green Chemical principals existed. For example, ACS's own "History of Green Chemistry" 10 stated, regarding the 1980s, that:

Until the 1980s, the chemical industry and the EPA were focused mainly on pollution clean-up and obvious toxins, but a major paradigm shift began to occur among chemists. Scientists, who came of age during the decades of growing environmental awareness, began to research avenues of preventing pollution in the first place. (Bolding added) Leaders in the industry and in government began international conversations addressing the problems and looking for preventative solutions.

The remainder of this article will focus on and elaborate on some early and underrecognized industrial examples of "Green Chemistry" that were practiced commercially long before the 1990's, in both the bulk chemical and then the fine chemical/pharmaceutical industry. This article will also discuss and document some of the human, cultural, and economic factors that co-evolved with the technological advances during the "prehistory" of Green Chemistry.

\section{Industrial precursors of "Green Chemistry"?}

Prof. Roger Sheldon, who was one of the earliest and most well-known public champions of Green Chemistry, spent many years in chemical industry before moving to academics in 1991. ${ }^{11}$ Sheldon published a 1992 Chemistry \& Industry article (Sheldon 1992) entitled "Organic Synthesis- Past, Present, and Future." Prof. Sheldon commented that:

The major reason for the decline of classical organic synthesis has been the increase in environmental awareness. The chemical industry is under increasing pressure to minimize or, preferably, eliminate waste production in chemicals manufacture. Integrated waste management, zero emission plants and environment-friendly processes are now commonly heard catch phrases in the chemical industry. (Bolding added).

In 1993 Chemical Engineering Magazine ${ }^{12}$ awarded its biannual "Kirkpatrick Award" for "outstanding group effort in developing and commercializing chemical process technology" to BHC's Ibuprofen process (further described below). The first three sentences of the Kirkpatrick Award article stated;

Increasing the efficiency of a process is an ongoing directive in the chemical process industries (CPI). Minimizing its impact on the environment is another. Traditional bulk-pharmaceutical manufacturing could use help on both counts. (Bolding added).

\footnotetext{
${ }^{10}$ See http://www.acs.org/content/acs/en/greenchemistry/what-is-green-chemistry/history-of-green-chemis try.html.

11 Prof. Sheldon was at Shell Research Laboratories in Amsterdam from 1969 to 1980, and from 1980 to 1990 he was Vice President for R\&D with DSM-Andeno. In 1991 he was appointed Professor of Biocatalysis \& Organic Chemistry at Delft University of Technology. He recently moved to the School of Chemistry, University of the Witwatersrand, Johannesburg, Republic of South Africa.

12 Chemical Engineering Magazine, December 1993, p. 94, "The Award Goes to BHC."
} 
As will be documented below, not only were "Integrated waste management, zero emission plants and environment-friendly processes ... commonly heard catch phrases," but they were already part of the culture and in actual commercial practice in some industry segments long before 1992 !

Professor Sheldon identified (Sheldon 1992, p. 904) an industry segmentation of the existing industrial eco-friendly processes:

The seriousness of the problem is readily appreciated by considering the amount of waste produced per kilogramme of product - the 'E factor' in various segments of the chemical industry (see Table 1).

Sheldon's "E-Factor" is now in routine use as a measurement metric in Green Chemistry research.

But why was the E-factor in the oil and petrochemical segments of the industry so much lower than in the fine chemical and pharmaceutical segments? Prof. Sheldon suggested that "The chemical industry is under increasing pressure to minimize or, preferably, eliminate waste production in chemicals manufacture." (Sheldon 1992, p. 904)

This author agrees that there was increasing pressure on industry to eliminate wastes prior to the 1990s. This author and many other industrial scientists of the time clearly understood that increasing environmental awareness and governmental regulations would make it likely that waste disposal would become more difficult in the future, and that the associated waste disposal costs would continue to rise. But this author believes that governmental regulations and "increasing environmental awareness" had only relatively recently become part of the "pressure". There were other strong motivations for minimizing wastes in the oil and bulk chemical industries in the 1970s and 1980s, especially economics and competition!

Oil and bulk chemicals are low priced commodities selling for only pennies a pound, with even smaller marginal profits per pound. The cost of the raw materials is a big fraction of total costs in oil and commodity chemical industries, and the conversion of those raw materials into waste, compounded by increasing waste disposal costs, became increasingly damaging to profitability in the oil and bulk chemical industries, over decades. Accordingly, there were strong financial and competitive incentives in the oil and bulk chemical industries to improve their processes to maximize the productive use of raw materials and minimize their conversion to wastes. As a result, over decades, the oil and bulk chemical industries worked to evolve and improve the efficiency of their processes and products, and minimize waste, often by use of catalysts, even though they were often secretive about their technical and strategic details (for competitive and intellectual property reasons). Some relevant examples of such decades-long evolutionary processes will be described below.

In contrast, in the fine chemical and pharmaceutical industry segments the products tended to be more complex molecules, and the value, price, and per pound profit margins of fine chemical and/or pharmaceutical products was typically much higher. If the solvents, protecting agents and/or inexpensive acids and bases that were used in traditional synthetic organic chemistry were used during research, and later during manufacture, and then removed or neutralized to produce wastes, the cost for disposing of the relatively small absolute amounts of waste created was often low compared to the high price and profitability of the products. Therefore, for decades the economic incentives to avoid the use of 
Table 1 The E Factor. (from Sheldon 1992, used with permission of Prof. Sheldon)

\begin{tabular}{lll}
\hline Industry segment & Product tonnage & Kg byproduct/Kg product \\
\hline Oil refining & $10^{6}-10^{8}$ & ca. 0.1 \\
Bulk chemicals & $10^{4}-10^{6}$ & $<1-5$ \\
Fine chemicals & $10^{2}-10^{4}$ & $5->50$ \\
Pharmaceuticals & $10-10^{3}$ & $25->100$
\end{tabular}

stoichiometric reagents and acid and base auxiliaries were low in the fine chemical and pharmaceutical industries. ${ }^{13}$

\section{Evolution of low waste catalytic technologies in the early commodity chemical industry}

Over decades prior to the 1990s, many of the oil and commodity chemical industries achieved economically and environmentally desirable low waste production by evolving sophisticated and specialized catalytic processes for making their typically low priced chemical products. Celanese, the dominantly commodity chemical company where this author started his career was no exception. This author will use the processes developed and employed by Celanese and its industrial competitors, to commercially produce acetic acid and its derivatives, as convenient examples to illustrate the evolutionary processes that produced many early examples of low waste processes throughout the oil and commodity chemical industries. As will be described below, the cultural and strategic thinking and catalytic technologies invented, developed, and used for commercially for producing acetic acid were important technical and strategic inspirations for the BHC ibuprofen process invention.

Aqueous solutions of acetic acid (vinegars made via fermentation) were known very early in human civilization. Hermann Kolbe first synthesized pure acetic acid from the elements in 1845. By 1910, glacial acetic acid was being produced on the ton scale in Germany by treatment of the "pyroligneous liquor" obtained by pyrolyzing wood in airless containers during charcoal production, then treating the resulting dark liquid liquor with "milk of lime," and then the resulting calcium acetate was acidified with sulfuric acid to liberate acetic acid, along with stoichiometric amounts of calcium sulfate waste.

Celanese was founded in 1912 in Switzerland, by Henri Dreyfus, as a manufacturer of cellulose acetate (made by treating cellulose fibers with acetic anhydride). Celanese has always since been a major producer of products derived from acetic acid (including polyvinyl acetate and polyvinyl alcohol, major modern commodity products made from acetic acid). Over decades, Celanese and Dreyfus filed thousands of patent applications for improved methods of making acetic acid, acetic anhydride, and their derivatives. Starting in the 1920's (after WWI) the acetic anhydride Celanese required was prepared (at least partially) by a process of generating ketene by vapor phase dehydration of acetic acid at very high temperatures $\left(700-750{ }^{\circ} \mathrm{C}\right)$, followed by rapid reaction of the ketene generated with another mole of acetic acid.

\footnotetext{
13 It is well worth noting that in 1952 Peterson and Murray of Upjohn published their discovery of a regiospecific and enantiospecific microbial hydroxylation of progesterone to $11 \alpha$-hydroxyprogesterone that led to a 9 step commercial synthesis of cortisone, which replaced a 31 step chemical synthesis. This combination of economic. Public health, and ecological advantages were truly remarkable.
} 
After World War II, demand for acetic acid and related products increased, and petroleum and natural gas were very cheap and readily available in the Texas oilfields. In 1946 Celanese opened a process development and support laboratory near Corpus Christi Texas, and in 1952 Celanese opened a new chemical plant for making commodity acetic acid and acetic anhydride in Pampa Texas.

The Celanese Pampa process produced acetic acid, propionic acid, formic acid, and methyl-ethyl-ketone, and smaller amounts of several other low molecular weight organic oxygenates, by controlled but only modestly selective radical air oxidation of liquid butane under high temperature and pressure, using cobalt salts as catalysts. The catalytic method eliminated the salt wastes that had been produced by prior processes, but separation and purification of the mixture of organic products required an energy intensive "forest" of industrial distillation columns and solvent extractors. Furthermore, the reactor off-gas stream, even after organic product recovery, contained large amounts of carbon monoxide, carbon dioxide, and various low level organic wastes that had to be flared. However, despite its limitations, the Pampa process was a big improvement over prior technologies and was economically viable for many years, despite rising oil/gas prices later. Similar processes for manufacturing acetic acid by butane oxidation were also commercially practiced by Union Carbide, Standard Oil, Huls, and AKZO for many years.

In 1988, the Pampa plant suffered a major explosion that killed three people and injured thirty, and parts of the plant were rebuilt over almost 2 years. In 2003, a catalytic oxidation unit was added to deal with organics and carbon monoxide in the reactor off-gas waste stream, and/or an electric co-generation unit was added to reclaim some of the heat energy previously wasted. ${ }^{14}$ But as better acetic acid technologies evolved (see discussion below) the Pampa process finally became economically and environmentally obsolete, and was shut down in 2009.

In the meantime, other better technologies for making acetic acid-related products had evolved at Celanese's competitors. Advances in oil drilling and refining technologies were bringing down the price of ethylene and propylene. In 1956, a new process for the air oxidation of ethylene, in the presence of water solvent to produce acetaldehyde, using soluble tetrachloropaladate and copper chloride salts as catalysts, was developed at Wacker Chemie and Hoechst (Reinhard 2009; Eckert et al. 2012).

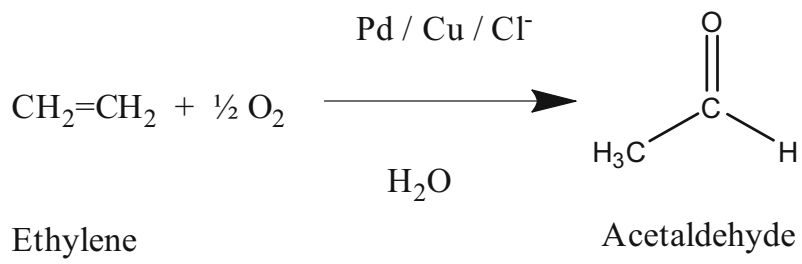

The mechanism of the homogeneous palladium catalyzed Wacker process is very complex (as are many catalytic systems), but has been very well studied in detail, and can be shortly summarized by the equations below.

${ }^{14}$ See Zero Waste Network case study at http://www.zerowastenetwork.org/success/story.cfm?StoryID=91. 


$$
\begin{array}{r}
{\left[\mathrm{PdCl}_{4}\right]^{2-}+\mathrm{CH}_{2}=\mathrm{CH}_{2}+\mathrm{H}_{2} \mathrm{O} \rightarrow \mathrm{CH}_{3} \mathrm{CHO}+\mathrm{Pd}+2 \mathrm{HCl}+2 \mathrm{Cl}^{-}} \\
\mathrm{Pd}+2 \mathrm{CuCl}_{2}+2 \mathrm{Cl}^{-} \rightarrow\left[\mathrm{PdCl}_{4}\right]^{2-}+2 \mathrm{CuCl} \\
2 \mathrm{CuCl}+1 / 2 \mathrm{O}_{2}+2 \mathrm{HCl} \rightarrow 2 \mathrm{CuCl}_{2}+\mathrm{H}_{2} \mathrm{O}
\end{array}
$$

The overall oxidation of ethylene to acetaldehyde is perfectly atom economical in theory, proceeds to high actual yields, and was carried out in water as solvent (as of 1956!). But the presence of the copper chloride co-catalyst salts, as well as corrosive $\mathrm{HCl}$, was required to prevent the precipitation of the expensive palladium catalyst. Maintaining very efficient performance and recycle/regeneration of expensive metallic catalysts is a recurring challenge, especially in Real World commercial production, as will be seen again and again below. Also, high cost corrosion resistant alloys were required for construction of the reactors and some other commercial equipment for the Wacker process. Celanese licensed the Wacker process and opened an acetaldehyde plant in Bay City Texas in 1962, and combined the Wacker acetaldehyde product with a catalytic air oxidation of the acetaldehyde to produce acetic acid.

It isn't widely known, but small percentages of toxic mono-, di-, and trichloro-acetaldehyde byproducts were produced by the Wacker process, and had to be dealt with on commercial scale. An aqueous waste stream from a distillation column containing those toxic chlorinated aldehydes was disposed of in (then legally permitted) deep ground injection wells. But that toxic waste stream was a continuing nagging concern for Celanese chemists, engineers, and management. At the Celanese Corpus Christi laboratories, at intervals another chemist or engineer would be assigned to take yet another look at methods for eliminating or better disposing of the chlorinated acetaldehyde waste stream (though none was ever found to my knowledge).

Nevertheless, as ethylene prices escalated, and new and better technologies (such as methanol carbonylation to be discussed below) became commercially practical, the Wacker process became less and less competitive, economically and environmentally. The Celanese Bay City Wacker acetaldehyde plant was shut down in 1994.

Celanese responded to market needs and their competition by becoming a commercial practitioner of syngas-based high efficiency technologies for making several commodity chemical products. "Syngas" is a mixture containing potentially varying ratios of hydrogen and carbon monoxide. Syngas is typically produced commercially from methane (natural gas), via the steam reforming reaction, as follows:

$$
\mathrm{CH}_{4}+\mathrm{H}_{2} \mathrm{O} \rightarrow \mathrm{CO}+3 \mathrm{H}_{2}
$$

Syngas can also be efficiently commercially produced from coal and/or coke. The hydrogen and carbon monoxide can be efficiently separated on an industrial scale. Variations on these processes can be used to adjust the $\mathrm{H}_{2} / \mathrm{CO}$ ratios produced. Recently, numerous investigators are investigating producing syngas from biomass or waste sources.

One major use of syngas is for the industrial scale manufacture of methanol, and subsequent oxidation of the methanol is used to manufacture formaldehyde. Both the methanol and formaldehyde processes are practiced commercially on a large scale (via catalytic methods) by several companies, including the Celanese plant in Bishop Texas: 


$$
\begin{aligned}
& \mathrm{CO}+2 \mathrm{H}_{2} \stackrel{\text { catalyst }}{\longrightarrow} \underset{\begin{array}{c}
\mathrm{CH}_{3} \mathrm{OH} \\
\text { Methanol }
\end{array}}{\longrightarrow} \\
& \mathrm{CH}_{3} \mathrm{OH}+1 / 2 \mathrm{O}_{2} \stackrel{\text { catalyst }}{\longrightarrow} \mathrm{CH}_{2}=\mathrm{O}+\mathrm{H}_{2} \mathrm{O}
\end{aligned}
$$

The catalytic processes for producing methanol and formaldehyde are atom economical in theory, and very efficient in Real World practice. But formaldehyde has an inherently disagreeable odor at very low concentrations in air. For many years, the sparse population around Bishop Texas used to call Celanese "Smellanese." I'm told the formaldehyde odor problem around Bishop is better nowadays, due to much improved engineering controls.

A downstream syngas-based catalytic process soon took over from the Wacker ethylene/acetaldehyde process for making acetic acid mentioned above, namely methanol carbonylation, the reaction shown below:

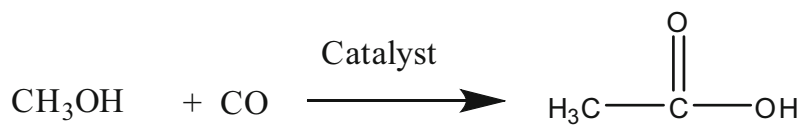

The product acetic acid serves as the solvent in commercial production. The following description of the development and evolution of methanol carbonylation technologies illustrate the complexities that can be involved in the use of catalysts and catalytic reactions.

Workers at BASF initially discovered the methanol carbonylation reaction using cobalt/ iodide catalysts in 1913, and commercially useful quantities of methanol became available in 1920 (after WWI). Henry Dreyfus at British Celanese developed a methanol carbonylation pilot plant as early as 1925 (see LookChem website article "Carbonylation of Methanol to Acetic Acid", and Wagner 1978), but lack of sufficiently corrosion resistant metals for plant construction delayed commercialization. After advances in metallurgy occurred in the 1950s, the first commercial methanol carbonylation process, which used a cobalt/iodide catalyst at a pressure of several thousand psig, was first commercialized by BASF in 1960.

In 1968, a rhodium-catalyzed methanol carbonylation catalyst (i.e. cis $-\left[\mathrm{Rh}(\mathrm{CO})_{2} \mathrm{I}_{2}\right]^{-}$) was discovered at Monsanto (Paulik et al. 1973; Roth 1975), which could operate efficiently at much lower pressure (a few hundred psig), and produced few by-products. The efficiencies based on methanol are extremely high, and the efficiencies based on carbon monoxide were in the low 90\% range. Monsanto Company built the first plant using the original Rh/I catalysts in 1970. Celanese licensed the process from Monsanto, and built a plant in Clear Lake Texas in 1975. "Monsanto" rhodium-catalyzed methanol carbonylation became the dominant method of acetic acid production for years, but with further evolutionary improvements to be discussed below.

The rate determining step and/or "mechanism" of the original version of the Monsanto process was studied and partially described in the literature by multitudes of authors in the 1970s. Without attempting to detail this complex technical subject here, it is very well known that in the original Monsanto acetic acid/water/Rh/I catalyst solutions, methanol initially reacts with $\mathrm{HI}$ (which is present in situ) to form methyl iodide, and the methyl 
iodide so produced reacts with metal carbonyl catalysts such as the $\mathrm{Rh}(\mathrm{I})$ iodide complexes to initiate a catalytic cycle for the insertion of $\mathrm{CO}$ that produces acetic acid.

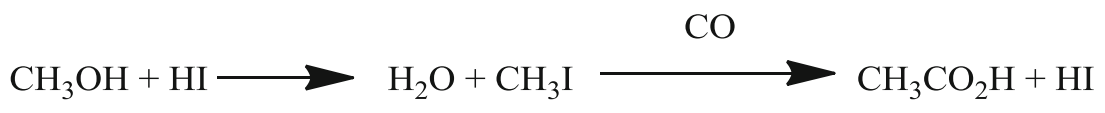

$\mathrm{Rh} / \mathrm{I}$

An important fact often ignored in the published articles describing the Monsanto methanol carbonylation process was that in order for the extremely expensive $\mathrm{Rh} / \mathrm{I}$ catalysts to remain active and stable in Real World continuous production, the catalyst solutions required the presence of large amounts of water, about 8 molar. Large and expensive high metallurgy distillation columns that consumed much energy were required for separation of the catalyst and water from the acetic acid product. If water concentrations were lowered, unacceptable amounts of Rh(III) compounds precipitated in the product isolation sections of the plants. The large amounts of water present in the original Monsanto process also caused side reactions that significantly decreased the yields based on carbon monoxide (Smith et al. 1987, 1991). The necessity for the undesirable presence of such large amounts of water in the Real World Monsanto process was not well understood or explained for years. Similarly, public descriptions of methanol carbonylation typically ignored the fact that methyl acetate is formed in large quantities in Real World catalytic systems, and that it's concentration was also very important to maintaining Rh catalyst activity and stability.

Nevertheless, simultaneously or even before, several industrial groups reported marginally successful attempts to adapt the $\left(\left[\mathrm{Rh}(\mathrm{CO})_{2} \mathrm{I}_{2}\right]^{-}\right)$catalysts to carbonylate methyl acetate, in the complete absence of water, to produce acetic anhydride, ${ }^{15}$ as shown below.

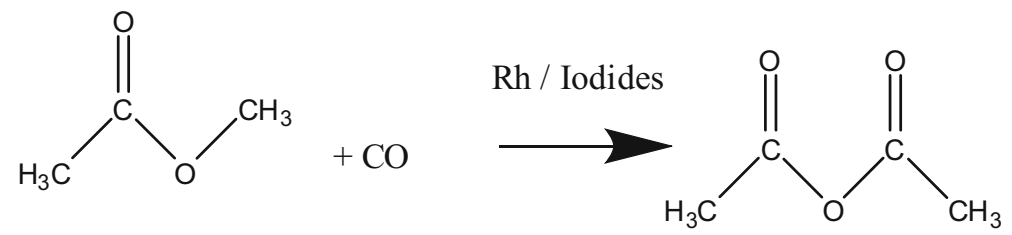

However, very serious problems were encountered with catalyst stability and tar formation in the absence of water. However, in 1982, a patent application from Eastman Chemical (Larkins et al. 1982) disclosed that the anhydrous carbonylation of methyl actetate to acetic anhydride could be successfully accomplished at high rates, with good Rh catalyst stability, and with little tar formation, provided substantial amounts of lithium iodide co-catalyst was added to the Rh catalyst, and a small partial pressure of $\mathrm{H}_{2}$ gas was maintained in the carbon monoxide gas feed. In 1983, Eastman successfully started up a commercial plant for the carbonylation of methyl acetate to acetic anhydride in Kingsport Tennessee, as part of a larger complex for making industrial chemicals entirely from coal (Zoeller et al. 1992; Zoeller 2009).

Although there are substantial similarities between the original Monsanto acetic acid process for methanol carbonylation and Eastman's process for carbonylating methyl

\footnotetext{
15 See for example Belgian Patent No 819,455 granted March 3, 1975; Japanese Patent Application Publication 75-47922, published April 28, 1970; US Patent 4,046,807 issued September 06, 1977; and European Patent Application 0008396, published March 5, 1980.
} 
acetate to acetic anhydride, there are also substantial differences. One of the differences is that under anhydrous conditions, little or no $\mathrm{HI}$ is actually present. In the presence of substantial amounts of methyl acetate and lithium iodide, the methyl iodide required for methyl acetate carbonylation is produced by a new equilibrium reaction shown below, which also produces substantial amounts of lithium acetate.

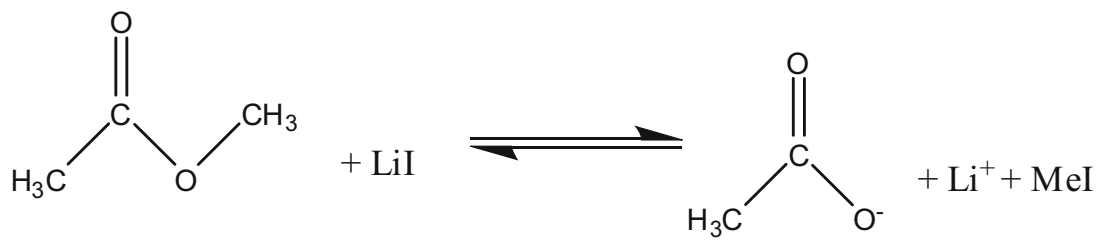

The presence of lithium acetate and lithium iodide, and the substantial absence of HI under such conditions have considerable technical and ecological importance in both methanol and methyl acetate carbonylation that will be better explained below.

Also in 1982, Dr. Adolfo Aguiló, Group Leader of a catalysis group at the Celanese Technical Center in Corpus Christi Texas, and Dr. G. Paull Torrence, a Senior Chemist in Aguilo's catalysis group, were tasked with finding ways to increase the production capacity of Celanese's "Monsanto" acetic acid plant in Clear Lake Texas. The biggest bottleneck in the Clear Lake plant was a large and highly expensive high-metallurgy distillation column, used for separating water from crude acetic acid.

Aware of the Eastman patent application, Aguiló and Torrence decided to build a labscale "micro-unit" mock-up of the continuous reactor and product separation stages of the Clear Lake acetic acid plant. They hoped to modify the Monsanto acetic acid process to operate at lower water concentrations, so as to "de-bottleneck" the acetic acid drying column, and therefore de-bottleneck acetic acid production at the Clear Lake Plant.

Aguiló also hired two new Ph.D. chemists just out of graduate school, Dr. Brad L. Smith from the University of Oregon, and this author, from the University of WisconsinMadison, to support their effort. Smith was immediately assigned to directly support Torrence and Aguilo's work in acetic acid process optimization (later named and used as an "AO" trademark by Celanese and Hoechst Celanese). This author was initially and primarily tasked to other exploratory projects briefly mentioned below, but also attended group meetings of the acetic acid research group.

Only a few months into 1983, Smith, Torrence, and Aguiló discovered that by adding lithium iodide to the Rh catalysts for "Monsanto" methanol carbonylation, and also substantially increasing the steady state reactor concentration of methyl acetate (which is formed in situ, and had previously hurt catalyst stability), water concentrations could be dramatically dropped from about 8 molar to about 2 molar, while still maintaining excellent activity and stability of the Rh catalysts (Smith et al. 1991). Not only did the lower water concentration under the new catalyst conditions dramatically de-bottleneck the distillation drying column, it also actually stabilized and increased the activity of the Rh catalysts! In contrast to Eastman's acetic anhydride process, no positive effect of $\mathrm{H}_{2}$ gas was observed under the new "low water" acetic acid conditions, and in fact the presence of $\mathrm{H}_{2}$ seemed to correlate with increased production of undesirable heavy byproducts.

Shortly after the initial discovery, this author was re-assigned to part-time supporting duties on the acetic acid team, such as work on room temperature model kinetic studies (Murphy et al. 1986) and catalyst stability studies (Smith et al. 1987). We found some 
evidence in both batch catalytic experiments and model kinetic studies for new reaction pathways involving coordination of iodide or acetate ligands to (cis $-\left[\mathrm{Rh}(\mathrm{CO})_{2} \mathrm{I}_{2}\right]^{-}$), to form in situ five coordinate di-anion $\mathrm{Rh}$ complexes that may have increased reactivity toward MeI. But it appears that at commercially relevant concentrations of lithium iodide and methyl acetate, any contributions from any such new reaction pathways are probably small.

An economically and environmentally important technical effect from the new "AO" ("Acid Optimization") catalysts was a much lower rate for the biggest waste-producing reaction in Monsanto methanol carbonylation, the water-gas shift reaction.

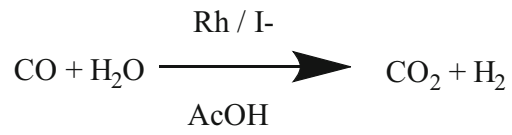

In the original Monsanto process, significant amounts of carbon monoxide and water get converted to $\mathrm{CO}_{2}$ and $\mathrm{H}_{2}$, and $\mathrm{HI}$ is intimately involved in the kinetics of that catalytic side reaction. Both $\mathrm{CO}_{2}$ and $\mathrm{H}_{2}$ wastes build up in the continuous reactor gas spaces, so that a vent gas stream must be continuously removed, and that gaseous waste stream must be waste-treated. Under the new "AO" conditions in a continuous reactor, where lithium acetate is present and the steady state concentration of $\mathrm{HI}$ and $\mathrm{H}_{2} \mathrm{O}$ is much lower, the water gas shift side-reaction runs much more slowly, greatly reducing the rate of $\mathrm{CO}_{2}$ and $\mathrm{H}_{2}$ waste production, allowing major reduction in the volume of the reactor gas vent waste stream, and thereby substantially increasing the $\mathrm{CO}$ efficiency and very significantly lowering production of dilute $\mathrm{CO}_{2}$ and $\mathrm{H}_{2}$ waste. Moreover, the Rh catalyst solutions are stabilized, and methanol carbonylation rates increase, likely because the steady state ratio of $\mathrm{Rh}$ catalyst complexes in the $\mathrm{Rh}(\mathrm{I})$ forms (active for methanol carbonylation), as compared to catalytically inactive $\mathrm{Rh}(\mathrm{III})$ salts (that can be present at some process locations and can lead to precipitation of $\mathrm{Rh}$ from the solutions) is significantly increased. (Smith et al. 1987).

The process improvements discovered in the AO project at Corpus Christi were initially put into production at the Celanese plant in Clear Lake Texas in the late 1980s, and the Celanese AO process has since been improved and expanded yet again. Clear Lake is now the largest acetic acid plant in the world, and has been reported in the industry press to produce about 1.2 million tons of acetic acid per year. Furthermore, according to Celanese press releases, Celanese built and started up similar AO-based acetic acid plants at Jurong Island Singapore in 2000, and at Nanjing China in 2007.

In May 2012, Celanese publicly announced that in order to try to take advantage of expected low natural gas prices in the US (as a result of the development of fracking oilfield recovery technologies) Celanese planned to build another new acetic acid plant (at Clear Lake Texas or in Louisiana) along with a new companion plant to make the methanol feedstock. Moreover, Celanese is also strongly considered adding a new process to the new Clear Lake complex, to hydrogenate acetic acid to make ethanol for gasoline blending (Johnston et al. 2011). This new Ethanol process would compete with corn/sugar based ethanol, which is well known to typically have poor energy efficiency and divert corn and cropland needed for human and animal purposes. However, no more recent announcements have been made about the acetic acid to ethanol process for making synthetic fuel.

Progress at Celanese did not stop further innovation and evolution at Celanese's competitors. Despite the complexities of catalyst research, development and use, in 2000, 
British Petroleum announced development and commercialization of a new methanol carbonylation technology for making either acetic acid or acetic anhydride, based on Iridium catalysts (Jones 2000), which also runs under "low water" conditions. Several commercial BP plants for manufacturing acetic acid using Ir catalyzed acetic acid processes are now in commercial operation.

Lastly, a separate set of commercial processes using syngas as a feedstock (and relevant to the conception of the ibuprofen process invention) was practiced by Celanese at its Bay City Texas plant, i.e. "hydroformylation" of olefins, especially propylene, to form aldehydes. The hydroformylation reaction (also often referred to as an "oxo reaction") of propylene is shown in the equations below:
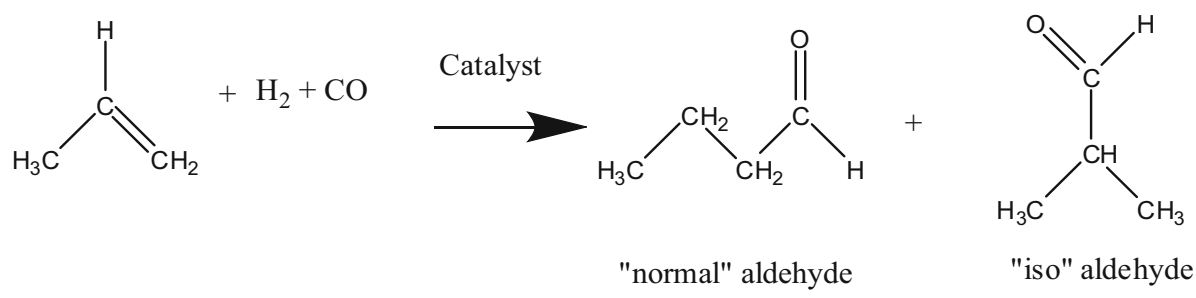

In commercial production, the aldehyde product (and heavy ends formed from the selfcondensation of the aldehydes) serves as the solvent for the hydroformylation reaction. The pure aldehydes are then hydrogenated to make alcohols, or oxidized to make carboxylic acids, or self-condensed to make higher aldehydes and then alcohols or carboxylic acids for use in plasticizers, lubricants, etc. As illustrated above, when substituted olefins are hydroformylated, mixtures of "normal" and "iso" aldehydes can result from any lack of regio-selectivity in the catalytic reactions.

The original commercial catalyst for hydroformylation of propylene (to make n-butyraldehyde, and then n-butanol) was a soluble $\mathrm{HCo}(\mathrm{CO})_{4}$ complex, at pressures of several thousands of pounds of syngas (Heck and Breslow 1961; Cornils et al. 1994), and the product contained undesirably high proportions of the less commercially valuable "iso" aldehyde. Subsequent evolutionary improvements in commercial "hydroformylation" chemistry involved the addition of trialkyl phosphines $\left(\mathrm{P}(\mathrm{n}-\mathrm{Bu})_{3}\right)$ to the cobalt catalysts, which improved the regio-selectivity for production of the commercially more desirable n-aldehyde.

In the 1970's new processes employing Wilkinson's catalyst, i.e. Rh-triphenylphosphine catalysts (Imyanitov and Rudkovskij 1963; Evans et al. 1994) substantially lowered the required pressures and further improved the normal/iso selectivity. These new Rh based catalysts were commercialized throughout the industry, including by Celanese at its plant in Bay City Texas. Celanese also used hydroformylation technology to manufacture some longer chain aldehydes, which were used to make synthetic fatty acids, and eventually synthetic lubricating oils. All these "hydroformylation" reactions were very high efficiency, low waste processes, and commercially practiced by Celanese and others by the late 1970's. This author never worked "hands on" on "hydroformylation" technologies, but regularly attended internal Celanese research group meetings and brainstorming sessions related to the hydroformylation technologies.

Some readers may be yawning and wondering: "Why retell this old chemical history?" Were there significant environmental improvements? The answer is yes. 
To cite an example, in 2010 Celanese published a report ${ }^{16}$ that compared the environmental differences between the Celanese acetic acid processes commercialized at Pampa Texas in the 1950's (and shut down in 2008), with the AOPlus ${ }^{\mathrm{Tm}}$ technology started up by Celanese at Nanjing China in 2007. A chart was presented, just after the Chairman and CEO's article titled "Sustainability is Good Business". It reported that as compared to the Pampa process, energy consumption at Janjing was 12 times lower, greenhouse gas emissions were 5 times lower, "Air" emissions were 12 times lower, and total wastes were 25 times lower. Clearly, environmental progress accompanied the oil and commodity chemical industry-wide technical evolution, and resulting financial and commercial successes.

\section{The cultural factors}

Other broadly important external social and cultural factors were also at work in both industry and the broader society in the 60's, 70's, and 80s. The Vietnam War ended in defeat for the US, and the Nixon/Watergate scandals rocked confidence in the US government. In reaction to the Arab-Israeli War of 1973, OPEC embargoed oil shipments to the US and some European countries, causing mass gasoline shortages and threatening the ultimate source and price of the raw materials used by both the international oil companies and bulk chemicals industries. Further downstream, Japanese cars and electronics began to flood into the US and Europe.

Also, after the political "malaise" of the Carter years, the fall of the Shah and following Islamic Revolution in Iran, and a terrible US economic "stagflation" of the late 1970s, many people from all walks of life began to wonder if significant change was needed in the developed countries, for both moral and economic reasons. Then the Three Mile Island nuclear accident in 1979 shook many people's faith in technology, and raised further environmental concerns.

Then Ronald Regan won the US Presidency in 1980, and the US Federal Reserve dramatically restricted the US money supply, to cure the extremely high US monetary inflation raging at the time. A deep recession resulted in the US during 1980 and 1981, and many companies (chemical and otherwise) in the US and abroad laid-off large numbers of workers, including researchers.

But when the US economy began to recover in 1982, many oil and chemical companies began to think again about a potentially uncertain longer-term future, and started hiring researchers again. Many oil companies began research programs directed toward producing synthetic fuels. Many chemical companies began to search for alternative feedstocks for their bulk chemical products, and also began efforts to diversify into the more profitable fine chemical and pharmaceutical markets.

This author believes that the human, political, cultural, governmental, economic, and technology crises of the 1960s and 1970s caused many Americans at all levels to begin to re-examine everything, and search for ways to improve their lives. This author believes that society-wide re-examination was a major factor in the rise of the "Quality" movement that swept American industry in the 1980s.

16 "Sustainability at Celanese 2010" is currently available in PDF form at http://www.celanese.com/EHS/ Sustainability.aspx. 


\section{W. Edwards Deming, Quality, and "Continuous Improvement"}

William Edwards Deming was an American engineer, statistician, professor, author, lecturer and consultant. ${ }^{17} \mathrm{He}$ is perhaps best known for his early work in post- WWII Japan. After the War, Deming taught top Japanese management how to rebuild their economy, by focusing the attention and efforts of both management and employees on improving design and execution of their production processes (and thus service), product quality, and sales through various problem identification and problem solving methods, with emphasis on the applications of statistical methods. In 1960, the Prime Minister of Japan, acting on behalf of Emperor Hirohito, awarded Deming Japan's Order of the Sacred Treasure, Second Class.

In June 1980, Deming was featured prominently in an NBC "White Paper" documentary ${ }^{18}$ titled "If Japan Can... Why Can't We?" The documentary (which can be viewed via the link provided in footnote 18) detailed the increasing industrial competition the United States was then facing from Japan, and highlighted Deming's early corporate consulting activities in Japan and the US.

Ford Motor Company was one of the first American corporations to seek help from Deming, in 1981, and GM, Dow Chemical, and other major national corporations followed suit. In 1986, Ford came out with a profitable line of cars, the Taurus-Sable line. In a letter to Autoweek Magazine, Donald Petersen, then Ford Chairman, said, "We are moving toward building a Quality culture at Ford, and the many changes that have been taking place here have their roots directly in Deming's teachings." President Reagan awarded the National Medal of Technology to Deming in 1987, and in 1988 Deming received the Distinguished Career in Science award from the National Academy of Sciences. Deming passed in 1993. Multiple books have since been written about his life and accomplishments, see for example Gabor (1990) and Gluckman (1993).

Deming's teachings rejected many tenets of traditional American management theories, and rejected traditional numerical financial or "management by objective" methods and goals. Deming instead emphasized teaching upper management to instead focus on leadership, and on enabling and training lower level managers and employees to focus on the details of improving their own work and production processes, and customer needs, via "Continuous Improvement" and use of statistical and non-statistical tools for problem identification and problem solving.

In his book "Out of the Crisis" (Deming 1982, 2000), ${ }^{19}$ Deming said:

To manage, one must lead. To lead, one must understand the work that he and his people are responsible for. Who is the customer (the next stage), and how can we better serve the customer? An incoming manager....must learn from his people what they are doing and must learn a lot of new subject matter... Focus on outcome is not an effective way to improve a process or an activity. (Bolding added)

As we have already remarked, management by numerical goal is an attempt to manage without knowledge of what to do, and in fact is usually management by fear.

\footnotetext{
17 This section on Deming's personal history and teachings borrows substantially from the history given in a Wikipedia article available at http://en.wikipedia.org/wiki/W._Edwards_Deming, and various materials available on the website of the non-profit Deming Institute, (https://www.deming.org/), as supplemented by this author's own training and experience in Deming-based methods and Quality philosophy, and quotes from Deming's Book "Out of the Crisis," originally published in 1982.

18 To view the original NBC documentary, see https://www.youtube.com/watch?v=vcG_Pmt_Ny4\&feature= youtu.be.

19 This author certainly hopes readers will purchase and read Deming's original books. The quotations above are used with the permission of the MIT Press.
} 
An introductory comment in "Out of the Crisis" (Deming 2000, pp. 23-24) explained:

Failure of management to plan for the future and foresee problems has brought about waste of manpower, of materials, and of machine-time, all of which raise the manufacturer's cost and price that the purchaser must pay. The consumer is not always willing to subsidize this waste. (Bolding added) The inevitable result is loss of market. Loss of market begets unemployment. Performance of management should be measured by potential to stay in business, to protect investment, to ensure future dividends and jobs through improvement of product and service for the future, not by the quarterly dividend.

The teachings of W. Edwards Deming have been summarized as follows ${ }^{20}$ :

Dr. W. Edwards Deming taught that by adopting appropriate principles of management, organizations can increase quality and simultaneously reduce costs by reducing waste, rework, staff attrition and litigation while increasing customer loyalty. The key is to practice continual improvement and to think of manufacturing as a system, not as bits and pieces. (Bolding added)

Regarding the question of 'What is Quality?' Deming wrote (Deming 2000, p. 168);

Quality can be defined only in terms of the agent...In the mind of the production worker, he produces quality if he can take pride in his work. Poor quality, to him, means loss of business, and perhaps his job. Good quality, he thinks, will keep the company in business. All this is as true in the service industries as it is in manufacturing.

Quality to a plant manager means to get the numbers out and to meet specifications. His job is also, whether he knows it or not, continual improvement of processes and continual improvement of leadership.

The difficulty in defining quality is to translate future needs of the user into measurable characteristics, so that a product can be designed and turned out to give satisfaction at price that the user will pay. This is not easy, and as soon as one feels fairly successful in the endeavor, he finds that the needs of the consumer have changed, competitors have moved in...

Deming obviously believed "Quality" to be a semi-subjective matter which can vary by the specific details of job function, employee, product, and customer. Deming also recognized that Real World production and sales of products and/or services to Real World customers is inherently a multi-disciplinary activity, and strongly encouraged the formation of multi-disciplinary "Quality Circle" teams for most industrial projects.

Deming also advocated that all managers and employees need to study and/or understand what he called a System of Profound Knowledge, consisting of four parts:

1. Appreciation of a system: understanding the overall processes involving suppliers, producers, and customers (or recipients) of goods and services;

2. Knowledge of variation: the range and causes of variation in quality, and use of statistical sampling in measurements;

3. Theory of knowledge: the concepts explaining knowledge and the limits of what can be known.

${ }^{20}$ This passage was reported in the Wikipedia article as an excerpt from Deming's own training materials. 
4. Knowledge of psychology: concepts of human nature.

Deming believed that the details of what was going on the shop floor and in other low level functions was very important to producing good Quality, and therefore the psychology and strategies used for obtaining active participation and contributions from lower level employees absolutely required that those lower level employees be treated fairly and well.

Deming offered fourteen "key principles" to managers for transforming business effectiveness. A few of the fourteen principals most relevant to this article are copied below.

1. Create constancy of purpose toward improvement of product and service, with the aim to become competitive, stay in business and to provide jobs.

5. Improve constantly and forever the system of production and service, to improve quality, productivity, and waste, (Bolding added) and thus constantly decrease costs.

6. Institute training on the job.

7. Institute leadership (see Point 12 and Ch. 8 of "Out of the Crisis"). The aim of supervision should be to help people and machines and gadgets do a better job. Supervision of management is in need of overhaul, as well as supervision of production workers.

8. Drive out fear, so that everyone may work effectively for the company. (See Ch. 3 of "Out of the Crisis")

9. Break down barriers between departments. People in research, design, sales, and production must work as a team, in order to foresee problems of production and usage that may be encountered with the product or service.

11 .

a. Eliminate work standards (quotas) on the factory floor. Substitute with leadership.

b. Eliminate management by objective. Eliminate management by numbers and numerical goals. Instead substitute with leadership.

13. Institute a vigorous program of education and self-improvement.

Deming also had a list of "Seven Deadly Diseases" of American managers and workers.

They included:

2. Emphasis on short-term profits

4. Mobility of management

5. Running a company on visible figures alone

6. Excessive medical costs

7. Excessive costs of warranty, fueled by lawyers who work for contingency fees

In the opinion of this author, Deming's approach started with the principals and techniques of science and engineering, then considered the role of both the good and bad parts of human behavior and psychology, then combined it all into a system, process, and theory of Management that demonstrated its potential to make all the parts function better individually, and better together as a whole, out in the Real World.

Today many companies continue to educate their executives, managers and lower level employees in Deming's methods (though clearly some others do not). The non-profit W. Edwards Deming Institute, continues such education in Deming's methods, see https:// deming.org/. The W. Edwards Deming Center for Quality, and Competitiveness, at the Columbia Business School (established in 1991, see https://www8.gsb.columbia.edu/ deming/the_deming_cup) also annually awards a "Deming Cup" to world recognized 
business leaders who have made outstanding contributions in the area of operational excellence and have fostered the culture of continuous improvement in the organization. The winners include executives from IBM (2010), Intermountain Health and Chrysler Group (2011), Macy's (2012), Johnson \& Johnson (2013), Dupont (2014), American Express and Cleveland Clinic (2015), and Honeywell and Pepsico (2016). Furthermore, the Deming Prize, a global quality award currently administered by Japanese Union of Scientists and Engineers, has been awarded since 1951 to individuals and businesses that have successfully implemented Total Quality Management (TQM) programs, see https://en. wikipedia.org/wiki/Deming_Prize.

Since 1995, Dow Chemical has devoted a section of its website to its "Quality Culture" which is "achieved through teamwork and continual improvement." See http://www.dow. com/en-us/about-dow/our-company/beliefs-and-culture/quality-culture. It may not be mere coincidence that the very first Presidential Green Chemistry Award, in 1996 in the category of "Greener Reaction Conditions" was given to the Dow Chemical Company, for an invention entitled "100 Percent Carbon Dioxide as a Blowing Agent for the Polystyrene Foam Sheet Packaging Market. $^{21}$

\section{Quality at Celanese}

In the early 1980's recession, Celanese, like many of its competitors, laid off many employees, including research chemists and engineers. However, in the early 1980's, one of Celanese's major customers requested that Celanese implement a Deming-based Quality program, and Celanese complied. When Brad Smith (later one of the ibuprofen co-inventors) and this author first reported for work at Celanese in January 1983, one of our very first assignments was to attend a series of training sessions in Deming's Continuous Improvement methods. One of the trainers was Dr. Ed Zey, also later one of the ibuprofen inventors, who had been named the local site's first "Quality Manager."

The courses taught the use of Deming's various problem solving and statistical tools, but also taught the very important lesson that mis-interpreted and mis-used statistics, i.e. statistics based only on measurements of final outcomes, are very often deceptive and unreliable. Real World processes are often very complex, comprised of multitudes of smaller sub-processes, each one of which sub-processes can be and often are subject to their own non-random "special cause" intermittent and hard to predict variabilities. The intermittent and non-linear variabilities of the sub-processes and the interactions between the sub-processes often make measurements of overall final outcomes of a complex process unreproducible and unreliable. As a result, attempts to measure and then directly manipulate the final outcome of complex processes, based on measurements of final outcome, are very often unreliable, and attempts to make such direct adjustments of final outcomes based on direct measures of outcomes usually increases overall variability. As previously quoted above, Deming felt "focus on outcome is not an effective way to improve a process or an activity."

Deming (and the Celanese courses) taught that statistics could however be used as a tool to help diagnose such intermittent "out of control" variabilities, and then improve (in combination with other tools and common sense techniques) problems in the "out of control" sub-processes. Many of Deming's tools and problem solving approaches are

21 See the EPA's Presidential Green Chemistry Award Website at https://www.epa.gov/greenchemistry/ presidential-green-chemistry-challenge-1996-greener-reaction-conditions-award. 
based on the Scientific Method, ${ }^{22}$ and therefore approach such "out of control" problems systematically. As problems in the various sub-processes are systematically diagnosed, and then improved, the overall variability and predictability of the final outcomes of such Real World processes improve, and eventually can hopefully be more reliably adjusted.

Unfortunately, the Celanese training courses probably over-focused on Deming's statistical, and problem solving tools, and under-emphasized Deming's many teachings about leadership and human psychology. Many non-technical employees disliked mathematics, and strongly disliked being forced to use the charting and statistical techniques. Some of the Celanese research managers and chemists, particularly in the exploratory departments, were also skeptical. "We do exploratory research, and we very rarely do repetitive things, so how can we possibly apply the statistical techniques?" was an often-heard (and partially valid) complaint.

But this author was impressed by the overall Deming philosophy. I applied the statistical techniques to make sure my analytical instrumentation and methods were giving reliable measurements. I also studied Deming's broader teachings about "Appreciation of a system: understanding the overall processes involving suppliers, producers, and customers (or recipients) of goods and services," and "Theory of knowledge: the concepts explaining knowledge and the limits of what can be known." Unlike some colleagues, I took opportunities to learn more about the Real World details of Celanese's commercial processes and customer needs, a practice Management encouraged. Most of us also read weekly summaries of recently published patents and patent publications, for information published by other Real World practitioners that were related to Celanese's interests. I also came to appreciate Deming's teachings that many things that are important are "unknown and unknowable," but must be dealt with in the Real World. The un-predictabilities of human perceptions, desires and behaviors fit into that category, but had to be dealt with on a daily basis.

This author tried to apply Deming's techniques during the acetic acid "AO" project described above. My supervisor and mentor Adolfo Aguiló was skeptical about some of the Deming philosophy and techniques, but he absolutely believed in process improvement projects, and closely examining actual data. Aguiló demanded that the early AO team meet often to discuss, examine, chart, re-examine, and re-chart the many types of data we were collecting (with or without the Deming statistical techniques), in order to try to increase our understanding of, and find ways to improve the acetic acid process. It was very exciting and very satisfying to be a member of that early AO team, and be part of the big improvements and rapid progress toward commercialization the AO project produced. It was very easy to take pride in the AO work, and in the greatly improved results we were producing.

The AO acetic acid improvement project at Celanese, and the focus and pride in our work that came from using a Real World "Quality" process also had a big connection to this author's conception of the BHC ibuprofen process, as further described below:

22 One of Deming's major scientifically based strategies for quality improvement was his famous "Plan, Do, Study, Act" cycle, which he attributed to his mentor, Walter Shewhart of Bell Laboratories. See https:// deming.org/explore/p-d-s-a. More will be said below about the "PDSA" cycle. 


\section{The BHC Ibuprofen story}

This author reported to the Celanese Chemical Company commodity chemical research division in Corpus Christi Texas in January 1983. This author originally conceived the overall synthetic strategy for the BHC ibuprofen process in May of 1984. Through the efforts and collaborations of many individuals in the Celanese research, development, piloting, and management teams, a new commercial plant for producing 4000 tons per year of ibuprofen was started up in 1992 in Bishop Texas. In the interim Hoechst had acquired Celanese to form Hoechst Celanese. BHC was a 1988 joint venture between Boots PLC (the original inventors and producers of ibuprofen as an FDA approved prescription drug) and Hoechst Celanese.

The BHC ibuprofen process has been described by others, among other things, as an "elegant," "revolutionary", and a "light at the end of the tunnel" invention, loosely affiliated with the beginnings of Green Chemistry. The BHC Ibuprofen process won Chemical Engineering Magazine's biannual Kirkpatrick Award in 1993, and the first Presidential Green Chemistry Award for Alternative Synthetic Pathways in 1997, and has been cited and featured in multitudes of subsequent external publications. See for example prominent publications such as Nature (Poliakoff and Licence 2007), Cann and Connelly (2000), and Sheldon et al. (1992, 2007, 2010). Sheldon described the ibuprofen process invention in 2010 as "a source of inspiration for other pharmaceutical manufacturers."

The patent and trade secret laws strongly inhibit the willingness and ability of industrial inventors to publicly disclose details about their inventions, technologies, approaches, and personal stories. Accordingly, the story of the invention of the BHC Ibuprofen process has never been previously told by the inventors. It was however repeatedly mis-told by certain self-interested Celanese managers, who re-told their "narrative" 23 to both insiders and outsiders, who then in turn often repeated that narrative. Because the patents have now all expired, some important facets of the BHC ibuprofen story can be told with unusual detail and candor, from an inventor's perspective, a perspective actively concealed until now. In light of subsequent events, it now seems to be a story worth telling, for a wide variety of reasons.

\section{Education and training were factors}

The education and training of the ibuprofen process inventors (including this author) was an important aspect of the ibuprofen story. As one example, the education and training of this author (which did not seem unusual at the time, but now seems significant in retrospect), will be briefly described.

I got my start in science in 1976-1977 as an undergraduate researcher in the Tulane University chemistry laboratories of Professors Donald J. Darensbourg and Marcetta Y. Darensbourg, now of Texas A\&M University. A project in mechanistic organo-metallic photochemistry that would have gone to a graduate student at many larger chemistry departments was assigned to me as an undergraduate researcher. Two years of part-time work resulted in a senior honors thesis and three publications, two in the Journal of the American Chemical Society and one in Inorganic Chemistry. My "hands on" introduction to science with the Darensbourgs, and a semester's graduate level course in synthetic organic chemistry very much excited me. The Darensbourgs strongly encouraged me to

${ }^{23}$ Taleb has recently discussed the problems, deceptions, and self-deceptions that can arise from our mind's tendency to substitute "narratives" for genuine thought and analysis. See Taleb (2007, Chapter 6). 
pursue graduate school in chemistry, and I decided on the University of WisconsinMadison.

I spent my first year at Madison (1977-1978) in the Organic Chemistry Division, and took courses in applied spectroscopy and synthetic organic chemistry from Professor Barry M. Trost (then at Madison). Prof. Trost lectured very fast, and it was very exciting to have a chance to learn from a world-class leader in synthetic organic chemistry and applications of catalysis in synthetic organic chemistry. I honestly don't remember if he talked to us about atom economy, or not.

But I became increasingly interested in organometallics and catalysis. At Madison I interviewed to join the organometallic research group of Professor Charles Casey (later President of ACS), who was researching the mechanisms of organo-metallic reactions and the catalytic reactions of organometallic compounds. ${ }^{24} \mathrm{I}$ also interviewed with Professor Larry Dahl, who was investigating the synthetic and structural chemistry of the largest transition metal carbonyl clusters known at the time. Both men were members of the National Academy of Sciences.

Also at the time, Earl Muetterties, a Harvard-trained inorganic chemist, who had spent about 15 years at DuPont Central Research before moving back to academics (Cornell) in the 1970s, was prominently proposing that transition metal cluster compounds might be candidates for a new generation of industrial catalysts. Partially inspired by Muetterties' ideas, and by Professor Dahl's work on metal clusters, I ultimately decided to join Professor Dahl's group, but continued to attend organic chemistry seminars, and some Casey group meetings.

The synthetic/structural chemistry of large transition metal clusters proved more unpredictable and difficult than I anticipated. My research efforts struggled with some difficult problems with very large platinum cluster compounds, and I took five years to put together enough material for a passable Ph.D. thesis, which unfortunately didn't do much to break any major new scientific barriers.

Many academics of that time (and in my experience even now) strongly encouraged their "better" students to remain in academia, but "lesser" students often took industrial jobs. I had however obtained my Ph.D. degree, and learned a lot of organic and organometallic chemistry, which was useful for my personal goal of becoming an industrial chemist. Professors Dahl and Casey nevertheless continued to be supportive mentors to me, even later during my industrial career.

Over the subsequent years, Professor Roger Sheldon has repeatedly stressed the importance of catalysis to the beginnings of Green Chemistry. First in 1992 and later (Sheldon 1997, 2010) Sheldon argued that catalysis and synthetic organic chemistry originally evolved separately as academic and industrial disciplines, but that the beginnings of merger between those disciplines was important to the beginnings of Green Chemistry. This author believes that his own academic education was an early example of that 1960's and 1970's merger, which better developed the field of organometallic chemistry and its catalytic applications, and that the merger of the two fields helped lead toward Green Chemistry.

But a "multi-disciplinary" education was not unique to this author. Ibuprofen coinventors Dr. Brad Smith and Dr. Graham Mott had similar organometallic academic educations. But academic backgrounds may not have been the most important factors in

${ }^{24}$ One of Prof. Casey's students whom I also interviewed with was Dr. Stanley Polichnowski, later one of the co-inventors of the Eastman acetic anhydride process mentioned above. 
our education and training. In this author's opinion, the Real World education and training we received after arriving in industry may have been even more important.

\section{How the BHC Ibuprofen process invention actually occurred}

One thing I was told very soon after my arrival at Celanese, in no uncertain terms, by several veterans, was that any project or process that I proposed to work on that generated significant quantities of waste products, especially inorganic salts, would have a very large strike against it. That strong internal prejudice against processes that produced significant amounts of wastes was already very much a part of Celanese culture the day I arrived there in January 1983. Afterwards I didn't consider that anti-waste prejudice to be either a special burden, or a big horn I should blow loudly, I (and my Celanese colleagues) just considered it to be one of many considerations and multidisciplinary problems that would need to be solved before any final commercial success could be achieved.

My first project was to investigate potential new methods for making ethylene glycol and/or a potential new and related potential commodity product, 1,3-propanediol. My exploratory work soon focused in on potential catalytic processes for producing 1,3propanediol via "hydroformylation" of ethylene oxide with syngas mixtures, using previously un-reported Rhodium catalysts. After some very promising early discoveries starting in mid-1983, the project eventually consumed years of my individual efforts, and resulted in three families of patents (Murphy et al. 1989). Although we made considerable further progress, and discovered a lot about the Rhodium carbonylation catalyst chemistry, the 1,3-PDO project eventually (painfully) failed, because we were never able to identify a commercially feasible combination of the necessary yields, rates, and rhodium catalyst stability. However, 1,3-propanediol eventually did later become available commercially and proved useful for making a new and potentially superior polyester carpet fibers. $^{25}$

Yet another Celanese technology being pursued at Corpus Christi at the time was also relevant to the conception and reduction to practice of the BHC ibuprofen process. Celanese, like many other commodity chemical manufacturers at the time, was actively investigating new opportunities in fine chemicals and pharmaceutical intermediates, businesses which had higher profit margins than commodity chemicals. Celanese's fine chemical research group at Corpus Christi had identified and was developing a new process for making acetaminophen ("Tylenol", or "APAP"), via the reaction sequence shown below (Davenport and Hilton 1985).

${ }^{25}$ In 2003 Dupont won a Presidential Green Chemistry "Greener Reaction Conditions" Award for a process for making 1,3-propanediol via a biological process employing genetically engineered microorganisms. 


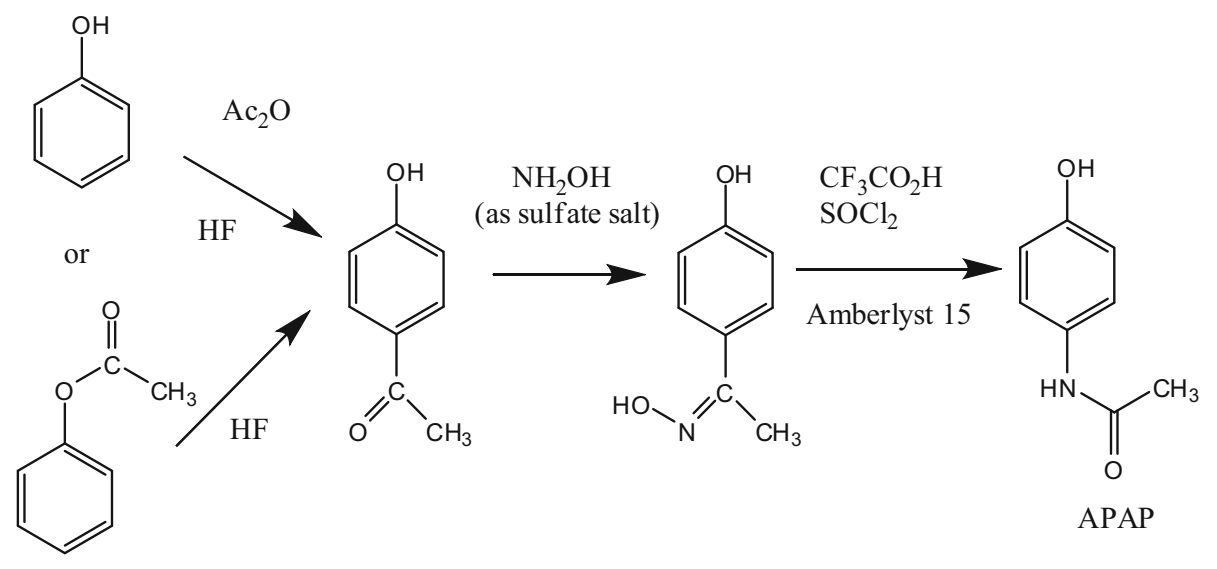

The Celanese exploratory fine chemical group had "re-discovered" the use of HF as a catalyst in the first "aromatic acylation" reaction steps shown above. Aromatic acylation reactions (using $\mathrm{AlCl}_{3}$ as a co-reagent) are of course taught in every sophomore organic chemistry class. The use of $\mathrm{HF}$ as a recyclable catalyst for alkylation reactions in oil refineries was known and had long been practiced commercially, but the dangers of the use of $\mathrm{HF}$ were also known. ${ }^{26}$ Furthermore, the use of $\mathrm{HF}$ (as an alternative to $\mathrm{AlCl}_{3}$ ) as a catalyst for the acylation of aromatics such as phenol, and/or the corresponding Fries rearrangement of phenyl acetate, to yield 4-hydroxy-acetophenone, had also long been known in the literature (Simons et al. 1940; Lewis 1958). But most likely because of the dangers and/or expense of working with and/or recycling HF, no commercial fine chemical processes had used $\mathrm{HF}$ as a catalyst for aromatic acylation reactions, a very broad class of reactions that are very commonly used in the fine chemical and pharmaceuticals industries.

The Celanese fine chemical researchers had however recognized the potential economic and environmental advantages of using and recycling $\mathrm{HF}$ as a solvent/catalyst. Use and recycle of $\mathrm{HF}$ avoided the production of wastes derived from use of $\mathrm{AlCl}_{3}$ as a stoichiometric co-reagent, but also very much increased the complexity and capital expense of building a custom commercial plant to handle and recycle such a dangerous and corrosive material as HF. During the APAP project, the Corpus Christi development teams developed the very significant and detailed technical know-how required to safely and economically use and recycle HF at commercial scale for a fine chemical/bulk pharmaceutical application. As a result of attending internal presentations describing the APAP project, this author (and the other Celanese chemists and engineers) were well aware of the advantages (and disadvantages) of the use of HF as an aromatic acylation catalyst.

Unfortunately, the Celanese APAP process ultimately also required use of several organic solvents, and produced a mole of acetic acid waste, and a mole of sulfate salt waste (because the hydroxylamine required for step 2 is supplied commercially in the form of a sulfate salt). The Celanese APAP process was commercialized at Bishop Texas in 1990,

\footnotetext{
${ }^{26}$ In oil refineries, mixtures of alkanes and alkenes are condensed in the presence of $\mathrm{HF}$ or $\mathrm{H}_{2} \mathrm{SO} 4$ to make higher alkanes. HF catalysts can be efficiently recovered and recycled. A 380 page Hydrogen Flouride Safety Study, and Final Report to Congress under Section 1112(n)(6) of the Clean Air Act was generated in 1993, after a refinery accident occurred in 1987. A copy of that report is available at http://www. documentcloud.org/documents/70516-epa-hydrogen-fluoride-study.html.
} 
but ultimately proved non-competitive, and the Celanese APAP plant was shut down in 2001.

In May1984 this author was granted a few days leave from the 1,3-propanediol and acetic acid projects. I went on my first professional development trip to the 10th Conference on Catalysis of Organic Reactions held in Williamsburg Virginia. I had the various pieces of background knowledge about the Celanese and Deming cultures and technologies described above swirling around in my head.

At the Williamsburg conference, Professor John K. Stille of Colorado State University ${ }^{27}$ gave a talk on "Asymmetric Hydroformylation via Polymer Supported Chiral Catalysts" (Stille 1985). In his conference presentation, Professor Stille discussed his group's work in use of polymer-supported and optically active rhodium bis-phosphine complexes as catalysts for attempted asymmetric hydroformylations of styrene, as shown in the equation below:<smiles>C=C([OH2+])c1ccccc1</smiles>

Styrene

$$
\mathrm{Rh}-\left(\mathrm{PR}_{2}\right)_{2} \text {-Polymer }
$$<smiles>CC(C=O)C(=O)c1ccccc1</smiles>

"iso"-aldehyde "normal" -aldehyde

At the conference, Professor Stille reported that his attempted asymmetric hydroformylations of styrene had only produced disappointing mixtures of the "iso" and "normal" aldehydes, and produced only very modest enantio-selectivity between the two optical isomers of the iso-aldehydes. Nevertheless, Stille verbally remarked at the conference, and again in his later published paper, that a high yield and more regio-selective and enantio-selective catalytic synthesis of appropriately substituted styrenes, to make the corresponding iso-aldehydes, might be relevant to a synthesis of "powerful analgesic, antiinflammatory drugs". One of Stille's conference slides showed several example structures of "profen" drugs, one of which was ibuprofen.

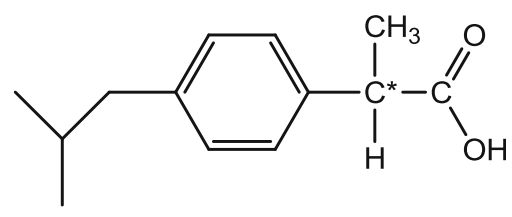

Ibuprofen

Prior to Stille's hydroformylation talk, I knew nothing at all about Ibuprofen. But in view of my personal interests in both catalysis and organic synthesis, and Celanese's interests in developing new commercial routes to fine chemicals and pharmaceuticals, I was very interested by Stille's work and concepts. Armed with Stille's hints, a general knowledge of organic chemistry, detailed information about Celanese's catalytic hydroformylation and $\mathrm{AO}$ acetic acid "carbonylation" chemistries, and the potential for use of

27 Prof. Stille deceased in 1989. Prof. Stille also invented the now famous palladium catalyzed "Stille" cross-coupling reactions of organo-tin compounds with aromatic halides or pseudo-halides. 
$\mathrm{HF}$ as an aromatic acylation catalyst, on that same evening at the Williamsburg conference I contemplated a multitude of possible schemes for making "profen" drugs.

Synthetic strategies involving styrenes and aldehydes seemed too long and complicated to be practical and economical. I recalled the "retrosynthetic analysis" discussions from my two graduate courses in organic synthesis. Looking at the structure of ibuprofen, and knowing a lot about catalytic carbonylation reactions, a catalytic carbonylation of a precursor alcohol to give the final carboxylic acid looked very interesting. The alcohol looked easily available from an acetophenone precursor via catalytic hydrogenation, a reaction that had been discussed in both my synthetic organic chemistry courses, and in House's classic graduate synthetic organic chemistry text (House 1972). The acetophenone seemed easily available by acetylation of a substituted aromatic, a reaction I had learned about in my first sophomore organic chemistry class. Accordingly, in just a few minutes that night I conceived a short general synthetic strategy for "profen" drugs! Adapting that general synthetic strategy to the ibuprofen case, that night in Williamsburg I conceived the strategy for the BHC synthesis of Ibuprofen, as illustrated below:

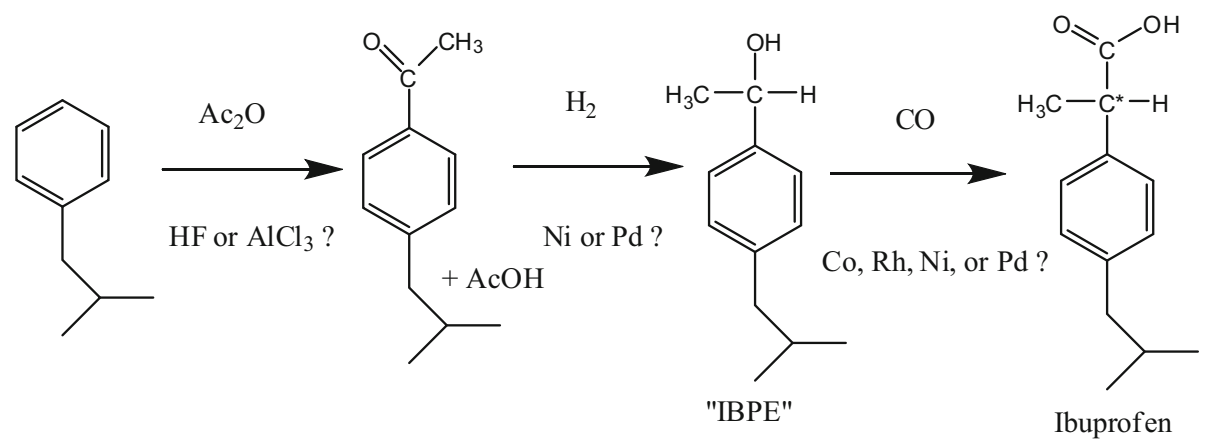

Before going home to Celanese, I consciously recognized the potential for low levels of waste products and/or potentially very high "atom economy" of my scheme. ${ }^{28}$ But low potential waste generation was only one of several "plus" factors for the idea. The scheme was short and simple, and therefore could potentially be very practical and economical. I had reasonable confidence that the first aromatic acylation step, and the second ketone hydrogenation step, could be quickly accomplished in good yields. The scheme seemed to have high potential "Quality."

From my personal knowledge and Stille's modest experimental results with styrene, I was however uncertain about whether a suitable transition metal catalyst for the last carbonylation step (to either the final carboxylic acid, or an aldehyde precursor) could be found that would sufficiently selectively produce the desired "iso" regio-chemistry and potentially optically active carboxylic acids. The last catalytic carbonylation step was clearly the technical and strategic key to the scheme.

I also immediately recognized that night that use of $\mathrm{HF}$ as a possible catalyst for the acylation step could potentially produce lower wastes, but I also knew the capital costs for building a specialized plant for using and recycling the potentially dangerous HF catalyst would likely be high. I had no idea if potential "profen" production volumes (which I

28 The term "atom economy" had not been coined at that time, but "un-enunciated" thinking in such terms was certainly part of the "culture" at Celanese and other commodity companies as well. 
didn't know) could justify such high capital expenditures. I also didn't know if ibuprofen (or other "profen" drugs from the class) needed to be optically active, or could be racemic.

I certainly had no idea at all what if any solvents might be ultimately necessary in a production process, nor about many other more specific chemical and mechanical process details. Such "details" were obviously unpredictable at the conceptual stage, and would obviously require experimental and developmental investigations, after suitable carbonylation catalysts that could produce the desired final products in acceptably high yields and selectivities could hopefully be identified.

Immediately upon return to Celanese, I wrote up a trip report that described Stille's hydroformylation work, and reproduced the structure of the "profen" drugs Stille had included on his slide, including ibuprofen. The Group Leader of the Celanese exploratory fine chemicals group read my trip report, and did some background searching on Ibuprofen as a potential new fine chemical/pharmaceutical product target. He found that ibuprofen was a USFDA approved prescription non-steroidal anti-inflammatory drug and painkiller that had been discovered and patented at Boots Pure Drug Company PLC (Nicholson et al. 1968), and that the US patents would be expiring in 1985. Moreover, the original Boots synthesis of racemic ibuprofen was long (six steps from isobutyl benzene) and generated a lot of wastes. The Exploratory Group Leader quickly invited all the on-site chemists to a brain-storming meeting to discuss new potential methods for making ibuprofen, as a generic drug opportunity that might complement the already on-going APAP project at Celanese.

At the brain-storming meeting, several other chemists proposed more traditional "organic chemistry" routes to ibuprofen. Then I wrote my catalytic carbonylation strategy for ibuprofen on the chalk-board. Dr. Charlie Hobbs, Celanese's resident expert on the Pampa acetic acid process, and most senior and respected chemist at Corpus Christi, came up immediately after the meeting to ask me multiple questions. He was very interested in the simplicity/elegance of the synthetic scheme, wherein each of the three steps was analogous to a catalytic chemical reaction Celanese had previously utilized commercially. Although I don't recall Charlie using the word, I still believe Charlie recognized the potential "Quality" of my scheme the first time he saw it.

I was quite busy with the early discoveries in my 1,3-propanediol work, and my parttime role in the AO acetic acid project. After the brainstorming meeting, Veraderaj Elango, a newly hired Ph.D. organic chemist from the exploratory fine chemicals group, was tasked with experimentally investigating the various proposed routes to ibuprofen. They chose to investigate the more traditional organic chemistry routes first, and spent several months doing so. It is important to note that in a Real World industrial laboratory, as compared to an academic setting, even this exploratory work would very likely not have been supported at all without an identifiable commercial target and/or objective.

But Dr. Brad Smith (my lab-mate and AO co-inventor) got a short break in his own acetic acid work. Smith did some literature searches on my proposed catalytic approach to ibuprofen. There had been substantial relevant prior work on prior similar routes to ibuprofen. Baddely et al. (1956) had disclosed the preparation of isobutyl-benzophenone by acetylation of isobutyl-benzene with acetyl chloride in the presence of aluminum chloride. A Japanese unexamined patent publication from 1980 and assigned to Mitsubishi Petrochemical Co. disclosed formation of ibuprofen by reaction of 1-(4-isobutylphenyl)ethanol ("IBPE") with carbon monoxide in the presence of HF catalyst. A very recent and relevant Japanese unexamined patent publication SHO 59 (1984)-95239 dated June 1, 1984 and assigned to Mitisubishi Petrochemical Co. disclosed that the Japanese were also investigating several catalytic carbonylation routes to various "profen" 
drugs. The Japanese patent publication contained a single unclaimed comparative example which showed an attempted carbonylation of IBPE with a palladium triphenylphosphine catalyst, to give an ibuprofen yield of only a discouraging $17.1 \%$.

Smith ran two experiments in an attempt to carbonylate 1-phenylethanol, as a model of the ibuprofen precursor (isobutylphenyl ethanol, "IBPE"), using Rh/LiI "acetic acid" type catalysts. Those two model experiments produced modest amounts of the desired model carboxylic acid, i.e. 2-phenyl propionic acid. Smith then had to return to his assigned acetic acid work.

No more work on my catalytic ibuprofen reaction scheme was done until Elango abandoned the more traditional organic chemistry routes to ibuprofen. But much to his credit, in a very short additional period of time, Elango began to obtain encouraging yields of ibuprofen by using a palladium/triphenylphosphine/aqueous $\mathrm{HCl}$ carbonylation catalyst, in the presence of solvents.

Within an additional short period of time, local Management of the exploratory fine chemicals group became encouraged by Elango's early lab results, the fact that each step in the very short and simple new ibuprofen process related to and was an evolutionary extension of chemistry and processes Celanese had used in the past, and the potential for low waste production.

There also appeared to be a very unique and attractive, but short-deadline market opportunity. The original Boots ibuprofen compound patent was about to expire, and ibuprofen was likely going to be approved for over-the-counter sales in the US, so that a market need for large production volumes could be expected, soon. But clearly if a new process for ibuprofen was to be commercialized, it had to be developed very quickly, before established ibuprofen suppliers filled the prospective ibuprofen market need with product made with the already established, but much longer and much dirtier processes.

Despite later public pronouncements that might make you believe otherwise, Celanese management was well aware of the potential dangers and disadvantages of using $\mathrm{HF}$ as an acylation catalyst, and was aware that the HF catalyzed aromatic acylation reaction needed for the ibuprofen synthesis was probably un-patentable in view of the prior art. A short and unsuccessful laboratory effort was made to investigate whether solid acid catalysts could be substituted for HF as the aromatic acylation catalyst.

Market and economic projections (based on draft process flow sheets that identified and considered all the inputs, outputs, and waste-related streams and costs) carried out by Celanese engineers concluded that the potential volumes of the new ibuprofen markets might well be large enough to justify the high capital cost of building a custom plant to safely handle and recycle HF. Therefore, even though the HF technology was clearly far from ideal, it looked better than the use of $\mathrm{AlCl}_{3}$, and it appeared it had a good chance to be successfully developed within the short market-determined timeline. Time was short and Management felt that Celanese could successfully evolve its pre-existing HF expertise and technology to develop HF catalysis and recycle for the 1st acylation step, and then on toward ibuprofen.

Together, all those factors justified the very rapid formation of a process development team in the fine chemicals division. That development team included co-inventor chemists, Dr. Graham Mott and Dr. Ed Zey, and a team of engineers with experience in handling HF in both continuous and batch processes, and pilot plants, including Gary Moss and Tom Kenneson. That team of people, plus many other team members, collaborated in the rapid development and then piloting of the Celanese commercial production and purification process. The first patent application was filed in March of 1987, which was first published 
as a European Patent Publication in November 1988, and eventually issued in the US in 1991 (see Elango et al. 1991).

The first step of the BHC ibuprofen process that team developed includes the use of HF as a recycled catalyst/solvent, in a continuous process using a counter-current loop reactor (Lindley et al. 1991). The second hydrogenation step was quickly developed as a solventless but otherwise conventional low pressure Raney Nickel batch hydrogenation of a ketone to an alcohol.

An organic solvent-less version of a two phase (aqueous $\mathrm{HCl} /$ molten starting material) batch carbonylation reaction, which produces the final ibuprofen product in high yield and efficiency, was developed by Joel Hendricks (an engineer) and chemist Graham Mott (see Elango et al. 1991; Hendricks and Mott 1992). That palladium-catalyzed carbonylation step maintains good palladium catalyst stability and recycle, even after ibuprofen product recovery.

Ed Zey, Thomas Shockley, and a team of others identified a short and successful scheme for purifying the ibuprofen (Zey et al. 1992). It is worth noting that three potential purification schemes were considered, and the one that produced the least waste and was selected for commercial production was conceived by Thomas Shockley, who was "only" a laboratory technician.

A pilot plant was built and operated in Corpus Christi by a team of chemists and engineers under the supervision of a local manager, Mr. Larry O. Wheeler. The pilot plant verified the planned production process and provided qualification samples of ibuprofen product for bio-equivalence testing, and samples to potential customers. Hoechst Celanese and Boots entered into a joint venture agreement to form the BHC company in 1988. Wheeler also supervised construction, start-up, and operation of the plant in Bishop Texas in 1992.

As actually commercialized in 1992, the BHC Ibuprofen process embodied six of the not yet published Principals of Green Chemistry, ${ }^{29}$ i.e. prevention of waste rather than treatment or cleanup, Atom Economy, minimization of solvents, energy efficiency, avoidance of protecting groups, and catalysis. Four of the later published Principals of Green Chemistry were irrelevant to the BHC ibuprofen process, namely designing safer chemicals, use of renewable feedstocks, designing for degradation, and real time analysis for Pollution Prevention. It violated two of the twelve Green Chemistry Principals, Less Hazardous Chemical Synthesis and Inherently Safer Chemistry, primarily because of its use and recycle of $\mathrm{HF}$ as an acylation catalyst, but nevertheless was an economic and ecological improvement over the prior use of $\mathrm{AlCl}_{3}$ for the very same acylation reaction in the prior Boots synthesis.

In 1995, BASF purchased both Boots and Hoechst Celanese's interests in BHC Company, along with the ibuprofen plant in Bishop Texas.

\section{So what did Quality have to do with it?}

So what did "Quality" have to do with the invention of the BHC Ibuprofen process, one of the very first and most well-known examples of Green Chemistry?

Louis Pasteur allegedly once said "Chance Favors the Prepared Mind." I agree.

The formal educations I and many others on the ibuprofen team had in several different relevant scientific and engineering fields, plus the Real World knowledge and hands-on-

${ }^{29}$ See the "12 Principals of Green Chemistry" at https://www.acs.org/content/acs/en/greenchemistry/whatis-green-chemistry/principles/12-principles-of-green-chemistry.html. 
experiences received at Celanese in commercial chemical products, process development and improvement projects, as well as the training we received in Deming's philosophy and tools, all contributed to "preparing our minds."

Much has been rightfully made recently of the impact of chance and highly unexpected and improbable events on human events and society, despite the best intent and efforts of "experts" (Taleb 2010; Mlodinow 2008). But when Professor Stille unexpectedly communicated the very modest results of his exploratory academic research work, and a hint about potential for a new product, Celanese and its teams of chemists and engineers were very well prepared mentally. We already had detailed knowledge of and expertise in the relevant isolated pieces of practical Real World technology, and we were able to very quickly recognize how to re-combine and mutate those previously evolved pieces of technology into a new combination. The end result was the "evolutionary" invention of a "revolutionary" new process for a new product, and the very rapid development of a Real World commercial process, all in time to meet a short-deadline market opportunity.

To add a little more detail, we had the benefit of excellent academic educations in multiple relevant fields of chemistry and engineering, from some excellent academic teacher/researchers. Our professors hadn't just lectured us, and then gone to their office and written and published their own theoretical papers in obscure academic or political journals. Our professors had taught and led their students by example. They shared their own research ideas with us (as graduate students) so we had an opportunity to apply our own minds and hands-on work to their ideas. Science, and extending and improving Science and technology, were almost always the focus in Chemistry graduate school, at least in my day. The Professors talked often about how to produce great Science, whether they actually called that approach a "Quality" approach or not. But they hardly ever lectured us about lofty-sounding political or social goals or objectives. Politics was rarely a topic of conversation among the students in the Science labs, except in mostly friendly debates at lunch.

What was however mostly missing from our graduate educations was a solid connection to the Real-World, every-day needs of customers, society and the markets, and the infinity of multidisciplinary issues and decisions typically involved in inventing, developing, and commercializing Real World technologies. Knowledge about those issues and problems and their solutions lay mostly outside the walls of the University laboratories. Our introduction to very complex Real-World technical, economic, environmental, and customer issues came in industry, not academia, or from government mandates.

At Celanese, we had absolutely no idea or goal at the time that our invention would start or become a significant part of a future "Movement" like "Green Chemistry". Evolutionary processes tend to work that way, see Dennett (1995). ${ }^{30}$ We were just trying to make new products for our customers in an efficient and waste-free manner, at a price they were voluntarily willing to pay.

Celanese had not previously had a strong reputation as a technical innovator company, but rather as an economically tight-fisted outfit that made it's living by relentlessly (and sometimes ruthlessly) improving its production technology for making commodity products. Deming's “Continuous Improvement” philosophy fit moderately well within the pre-

\footnotetext{
30 See "Darwin's Dangerous Idea-Evolution and the Meanings of Life," Daniel C. Dennett. Dennett's book was a 1995 finalist for the National Book Award and has been adapted as a PBS documentary. That book and others by Professor Dennett (about consciousness, free will, and their evolution) will be a major source for this author's planned future book titled "Dr. Murphy's Corollary_Law is Mostly a Bunch of Linear Approximations of a Non-linear World."
} 
existing culture at the Celanese labs and plants, even if upper Management often continued to do some important parts of the business (especially the financial stuff) in the old "do as I say, not as I do" ways Deming would have objected to.

Did learning about and employing a "Quality" approach solve all my problems, or bring a big personal reward at Celanese? The answer was clearly no, at least in my individual case. Some of the unfortunate facets of human behavior intervened.

The Exploratory Group Leader and his Research Manager from the Celanese exploratory fine chemicals group began to internally tell and very often repeat a narrative $\mathrm{e}^{31}$ to upper Celanese management, to the effect that the ibuprofen success was "really" just an outgrowth of their own prior "discoveries" related to HF chemistry. Celanese upper management (based at other sites), and later many other people inside and outside Celanese didn't know any better (up to and including the Presidential Green Chemistry evaluators, and most of the people who have subsequently read about the Presidential Green Chemistry Award for the BHC process). Most of them accepted local Celanese management's narrative version of the ibuprofen story without question, and have often repeated it later, in print and elsewhere.

Meanwhile, back at Celanese, Brad Smith and I realized that success often has many fathers (especially evolutionary successes), and that our own roles had been limited even if they were early and critical. We just kept our heads down and kept on working. Veraderaj Elango's contribution didn't get very much more recognition from Celanese Management. Our names were listed on the ibuprofen patent because legally they had to be listed, but were almost never mentioned again with respect to the BHC Ibuprofen Process, inside or outside Celanese. Meanwhile, the Exploratory Group Leader and the Research Manager reaped great personal/career rewards, and multiple promotions, by telling and re-telling their ibuprofen narrative.

Many scientists and engineers all over the world have subsequently recognized the "Quality" of the BHC ibuprofen process, including as an early example of Green Chemistry. But even now, when someone new mentions the BHC Ibuprofen process in the literature, they very often cite the use of HF in the acylation step as the most noteworthy part of the whole invention.

In this original inventor's opinion, the HF catalyzed acylation was clearly the weakest part of the overall scheme. It was clearly the final carbonylation step that was both the most novel, patentable, and most strategically crucial part of the ibuprofen synthetic scheme, at least from a technical and environmental perspective. Hardly anyone, except for Professor Roger Sheldon's (1992) Chemistry and Industry article, ${ }^{32}$ seemed to recognize the genuine roots of the synthetic strategy, and the connections of the BHC ibuprofen process to the commodity chemical thinking, culture, and the acetic acid catalytic technology.

I remained in Corpus Christi as a technical guy, by choice. After the 1,3-propanediol project finally finished unsuccessfully, I took a new position in the Celanese fine chemicals development/commercialization group, working on a new fine chemical product, tris-hydroxyphenyl-ethane ("THPE"), a polymer chain-branching agent that was in late development and/or initial commercialization. I worked on process improvements and

\footnotetext{
31 Taleb has recently said much about the dangers of operating on the basis of "narratives." See Taleb (2007, Chapter 6).

32 Prof. Sheldon remarked in 1992, at page 905, while describing the BHC Ibuprofen process, "Synthetic organic chemists would benefit enormously from the application of catalytic retro-synthetic analysis to identifying routes to a desired product. Indeed, the Hoechst Celanese route to ibuprofen was probably the result of such an analysis. Moreover, the fact that the key carbonylation step bears a striking resemblance to the modern technology for acetic acid manufacture is no mere coincidence."
} 
supervised/supported early commercial production at an external toll manufacturer, and traveled with a business development team to find and support potential new THPE customers. We managed to patent a small THPE process improvement (Murphy and Czarney 1993), and a new potential use for the THPE as a branching agent (Vicari and Murphy 1993).

In 1992, I had another idea, and originally conceived a new THPE derivative compound with a benzotriazole UV light stabilizing group attached, so that the UV stabilizing monomer could become co-polymerized into condensation polymers, and hopefully protect the polymers from UV light degradation (Murphy et al. 1993) Working together in our spare time, my new lab-mate Dr. George Kvakovszky and I managed to quietly synthesize the new compound, which we named THPE-BZT. We were just beginning to work (still in our "spare" time) to scale up the synthesis of THPE-BZT, in order to produce samples big enough for polymer testing, when the former Group Leader of the Exploratory fine chemicals unexpectedly returned to the Corpus Christi site again, this time as the new Manager of Exploratory Research.

Within a couple of months the new Research Manager decided to take the THPE-BZT project away from me, and take the project (and Kvakovszky) into his own research group. Frowning, I complied, and went back to my assigned work on THPE process/customer development and support. A few months later the new Research Director and a new chemist (who reported for work only after the THPE-BZT compound had already been synthesized) decided to give a paper entitled "THPE-BZT as a UV Stabilizer" at the Spring 1993 ACS National Meeting. I only learned about the ACS presentation, and the fact that my name had not been included as an author, the day before the paper was given at the ACS National meeting. Kvakovszky was also being treated extremely badly by the Research Manager, and was given no voice at all in the decision to present the ACS paper.

When the Research Manager returned from the ACS meeting, I went to his office and quietly asked why my name hadn't been included as an author of the ACS presentation. The Research Manager replied that he agreed a mistake had been made by omitting my name, and that he hoped we could both "forgive and forget," and go back to work. I quietly gritted my teeth, agreed, and went back to work.

Two months later, in mid-1993, I found a very short backdated "disciplinary" memo on my desk, vaguely alleging (without providing any further details) that I had been reprimanded two months earlier for unspecified "unprofessional behavior." I replied in writing to Hoechst Celanese, pointing out that the memo-number proved the "disciplinary" memo had only been written the day before, not two months before. I absolutely denied committing any "unprofessional behavior," and demanded to be informed about what I was being accused of. A few days later a series of falsified accusations and truly vicious and very personally directed retaliations occurred, then I was rapidly terminated.

The BHC ibuprofen plant had started up in 1992. I had become aware of Professor Sheldon's article publicizing the BHC Ibuprofen process as an example of Green Chemistry in 1992, before I was terminated at Celanese. I only learned of the 1993 Kirkpatrick Award from Chemical Engineering Magazine after I had been terminated at Celanese.

I sued the Research Managers involved, and Hoechst Celanese, in the state courts of Texas at Corpus Christi, for the common-law torts of defamation of character and intentional infliction of emotional distress. ${ }^{33}$ In the spring of 1995 , I proved to a jury the truth of what I've described above, and more. Professor Larry Dahl (my professor at Wisconsin,

33 Murphy v. *********, ********, and Hoechst Celanese Corp., 214 th Judicial District of Texas, Nueces County, Cause 93-6556-F. Documents from the case and trial are publicly available. 
who had briefly been a Celanese consultant) testified for me at the trial. The jury unanimously found the Defendants guilty, and awarded me a multi-million dollar damage award, before punitive damages were even to be considered. I believe the unanimous jury rendered a clear opinion as to who had and had not acted in a "Quality" manner.

Having cleared my name and reputation, and to avoid years of potential legal appeals, and for some family-related personal reasons, I settled with Hoechst Celanese after the jury verdict for a fraction of the jury's original award. While I had absolutely loved being a chemist, I never wanted to be treated like that again. I decided to go to law school at the University of Texas in Austin, and became a chemical/pharmaceutical patent attorney. I learned of the Presidential Green Chemistry Award while I was in Law School (1997), though nobody ever notified me or came to talk to me about the ibuprofen invention.

Also in 1997, Hoechst Celanese Management decided that the costs of the fine chemical/pharmaceutical research at Corpus Christi, and the more basic research at another Celanese research lab in Summit New Jersey were too high. Dramatic lay-offs were made at both Hoechst Celanese R\&D sites, leaving in place only a skeleton crew in Corpus Christi for commodity chemical support activities. In 2002, even the commodity chemicals activities were terminated and the Corpus Christi labs were closed.

Despite the true story above, this author doesn't believe Celanese, or Hoechst Celanese, were inherently "bad" organizations. Many fine people worked there, at many levels. Much was accomplished in Corpus Christi, both commercially and environmentally, before and during the time this author was there. But like many other large organizations (corporate and/or governmental), a few of Celanese's managers persisted in trying to directly manipulate inherently unpredictable final outcomes (especially financial and personal/ political ones), rather than focus on leading the workers and processes of the organizations toward continuous improvement. Some of those managers became corrupted by power, ego, greed, and/or personal ambitions, and did some very bad and/or stupid things. Everyone suffered for their bad actions.

It seems to this author that many corporate managers, politicians and governmental regulators, and even academics, of all political persuasions, from all over the World, regularly succumb to such things. Perhaps they could benefit from some mandatory training about "Quality," Leadership, and Deming?

\section{Holism, reductionism, MU, quality, and human guided evolution}

An important personal influence on this author has been the "Quality" philosophy described in Pirsig's (1974) bestselling book, "Zen and the Art of Motorcycle Maintenance, an Inquiry Into Values." 34 "Zen and the Art" is a semi-autobiographical philosophical novel that describes, via a beautiful and terrifying personal story, Pirsig's early experiences in the Sciences, and later attempts to build a new academic Philosophy based on "Quality."

Pirsig loved riding motorcycles, and the holistic, liberating, emotional, "in the now" joy that many people (including this author!) experience while riding a motorcycle. But Pirsig also loved repairing and maintaining his own motorcycle, and the rational, reductionist thinking he needed to understand the structure and functions of each part of his motorcycle, to be able to properly diagnose, repair and/or maintain the whole motorcycle.

34 Nothing about "Zen and the Art of Motorcycle Maintenance" was ever taught at Celanese. 
Pirsig's friends who rode with him also shared the holistic joys of riding a motorcycle. But some of Pirsig's friends couldn't understand, and were often suspicious of, and even feared, motorcycle maintenance and the rationalist/reductionist thinking involved in motorcycle maintenance. So Pirsig's friends hired "experts" to maintain their motorcycles rather than do it themselves, with very mixed results. Pirsig explored that seemingly small conflict between the holistic joys of motorcycle riding and his friend's distaste for the rationalist/reductionist thinking required to maintain the motorcycles. "Zen and the Art" used that small conflict as a metaphor for much larger, deeper and more general emotional and philosophical conflicts between holistic and reductionist viewpoints of Reality. Pirsig tried to resolve those larger conflicts in "Zen and the Art".

During his philosophical studies, Pirsig visited India for a time to study Eastern Philosophies and Religions, including Zen. Pirsig learned some valuable holistic attitudes and techniques for attaining "peace of mind", a mental state he found very useful and valuable, even while doing his rational/reductionist work. But Pirsig couldn't really accept Zen's typical total rejection of rational thought as a method for dealing with the uncertainties and unpredictability of life.

Pirsig returned to the US, and attempted to build an academic philosophy based on "Quality", as a solution to the general holism versus reductionism conflict. But despite his great efforts, Pirsig found he couldn't rationally define "Quality" in abstract general terms, even though both he and his students "knew what it was!". The reactions of the academics of Pirsig's time (the 1950s) to his inability to rationally and generally define "Quality" eventually resulted in some devastating personal setbacks for Pirsig. But Pirsig's eventual recovery and later writings about it all converted him into a world famous and best-selling author.

"Reductionism" can be rationally defined to be a mental viewpoint holding that "the whole is just the sum of the parts." Mathematicians, scientists, and engineers often hold and very often use such a view of Reality. In contrast, "Holism" can be rationally defined to be a viewpoint that "the whole is more than sum of the parts." Pirsig argued that his motorcycle, viewed as a whole, is something completely new, with new properties, new functions, and new "qualities" that are much more and much different than the mere sum of the pistons, cylinders, wheels, and other parts. These conflicting points of view regarding Reality can be and are of course debated.

In his 1979 Pulitzer Prize winning book, "Gödel, Escher, Bach; An Eternal Golden Braid, A Metaphorical Fugue on Minds and Machines In the Spirit of Lewis Carrol", Douglas R. Hoffstadter raised the "holism vs reductionism" debate to new and unexpected heights. A discussion of the wondrous variety of topics covered by Hoffstadter's book is impossible in this space, but included number theory, and Gödel's mathematical proofs that formal mathematical systems at sufficient levels of complexity can and do contain "undecidable propositions". Hoffstadter also rationally discussed the origin of life on the planet via evolution, and the origin and nature of intelligence and consciousness in the brain. Furthermore, Hoffstadter also explored the many ways in which artists like Escher assembled his brushstokes, and/or musicians like Bach assembled musical notes together, to produce holistically pleasing pieces of art.

Hoffstadter also discussed at some length the relevance of certain concepts from Zen, including the concept of "MU", which "unasks" many rationalist questions. Chapter 11 of Hoffstadter's book, entitled "Ant Fugue" deals extensively with "MU," as well as holist and reductionist ideas about how thought and consciousness emerge in the brain from the 
Fig. 1 A PDSA Cycle

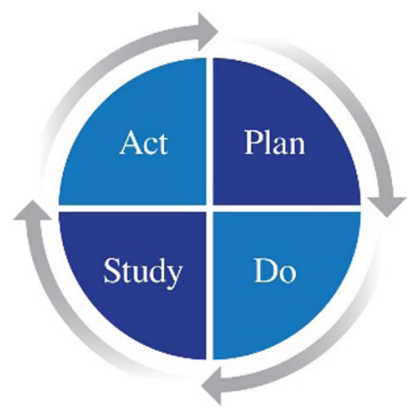

firings of individual neurons. ${ }^{35}$ A core message of Hoffstadter's Chapter 11 was that the holism-reductionism debate should be "unasked," because the workings of the brain cannot be understood solely in terms of the parts (the neurons and their relationships to each other) or solely in terms of the whole (thought and consciousness). Elsewhere in his book, Hoffstadter applied similar reasoning to the origins of DNA, proteins, and life itself on the planet. Again, Hoffstadter argued that his readers should "unask" the holist-reductionist debate, in order to attain a higher level of understanding of many important facets of the Real World.

Understanding Nature and Reality, from both a reductionist scientific viewpoint and a holistic/philosophical/emotional viewpoint, is quite a task. But going forward to artificially create a new material thing or process, and then get it out into an uncertain and unforeseeable Real World, is also quite a (somewhat different) task.

W. Edwards Deming, in his mostly systematic and reductionist communications style, nevertheless asked his followers to ask both reductionist and holistic questions, over, and over, and over again, using iterations of a systematic method known as a Plan-Do-StudyAct cycle. A diagram of a single PDSA cycle, and some explanatory comments (used courtesy of The W. Edwards Deming Institute ${ }^{\circledR}$ and its website, https://deming.org/ explore/p-d-s-a), is shown below in Fig. 1.

The cycle begins with the Plan step. This involves identifying a goal or purpose, formulating a theory, defining success metrics and putting a plan into action. These activities are followed by the Do step, in which the components of the plan are implemented, such as making a product. Next comes the Study step, where outcomes are monitored to test the validity of the plan for signs of progress and success, or problems and areas for improvement. The Act step closes the cycle, integrating the learning generated by the entire process, which can be used to adjust the goal, change methods, reformulate a theory altogether, or broaden the learning - improvement cycle from a small-scale experiment to a larger implementation Plan. These four steps can be repeated over and over as part of a never-ending cycle of continual learning and improvement.

Notice that only one PDSA step, the "Do" step, directly involves direct physical acts out in the Real World. The other three steps, "Plan", "Study", and "Act" are predominantly mental activities.

35 A copy of Hoffsteader's Chapter 11, as well as an explanatory commentary thereon, is available at http:// www.jimpryor.net/teaching/courses/intro/notes/mindsi11.html. 
Identifying a goal or purpose within in the Plan step can involve both holistic and/or reductionist considerations. Improving "Quality" is always a holistic goal, especially in view of customer desires and needs. Many customers may evaluate your final product or service primarily from a holistic viewpoint, and may not understand or even care about the reductionist parts of your thinking or your internal processes. But the customer's holistic viewpoint, needs, and desires should always be considered.

"Quality" may not be generally and abstractly definable, but a good scientist or engineer can often define many particular aspects of "Quality" more narrowly and in more reductionist and measurable terms, at least in the narrower context of the particular purposes, aspects, and technical details of Real World product or process or service being planned for. Potential for reductions in cost and/or waste should always be considered in the Planning stage.

Formulating a theory, defining success metrics and putting a plan into action are primarily but not exclusively reductionist questions and/or mental activities. If you are working on a complex product, or a product made by a complex multi-step process, you may need to narrow your focus toward and/or investigate a sub-process. Also, consult your team-mates, including the lower level team-mates. The theoretical process or sub-process you currently have in your mind may be different in subtle but important ways from the one that is actually happening out in the Real World plant, or in the field with the customers. Lower level team members, especially field people, may have some very valuable information about such things. They will probably communicate with you better and/or help you more if they subjectively believe you are treating them fairly and well, i.e. in a "Quality" way. After such communications, you may need to adjust your theory and other plans for subsequent actions.

In the "Do" step, you do your best to put the Plan into action as applied to the Real World process, or preferably a small scale test.

In the Study step, outcomes and/or success metrics from the "Plan" and "Do" steps are monitored to test the validity of the initial Plan for signs of progress and success, or problems and areas for improvement. Properly applied statistical methods and analysis can be extremely valuable in this Study step. Pay particular attention to results or data points that are outside normal statistical bounds (i.e. outside six sigma boundaries), they may well be hints about unexpected "out of control" sub-processes. Those "out of control" subprocesses probably deserve investigation and/or troubleshooting.

The Act step closes the cycle, integrating the learning, progress, and/or Quality improvements generated by the prior steps. The information learned can be used to adjust the goal, change methods, reformulate a theory altogether, or broaden the learning for the next cycle. If statistical analysis suggests that the measurable metrics have indeed been reliably improved, the team should consider standardizing the improvements in the Real World processes, thereby "locking in" any resulting gains in final Quality, with improved confidence that those gains can be maintained in the future in the Real World, without the need for costly inspection and rework schemes.

Hopefully your customers will notice and like the Quality improvements that have emerged from your "Quality" processes, but do not be surprised if some customers neither notice or even like your improved Quality. Those particular Qualities may not matter to some customers, even though they probably have value to you.

Notice that the PDSA cycle is based on the Scientific Method, but unlike traditional Scientific tradition, which is sometimes said to urge scientists try to always maintain an "objective/reductionist" perspective, the PDSA cycle approach readily incorporates both reductionist/objective perspectives and holistic/subjective and/or "Quality" considerations. 


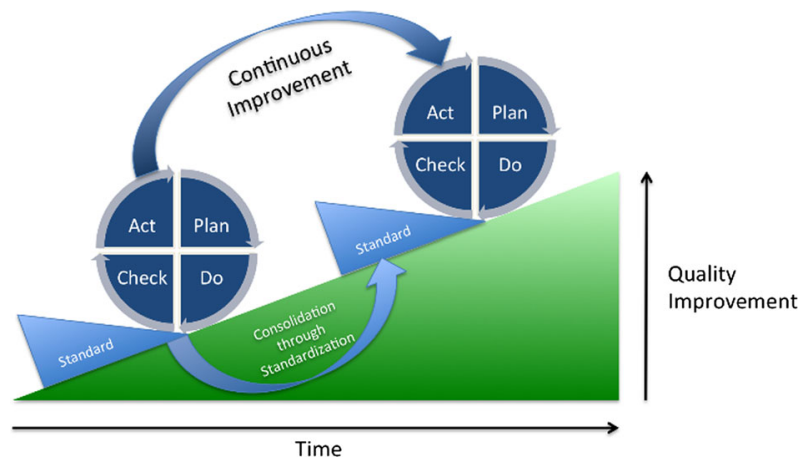

Fig. 2 The Effect of Repeating PDCA/PDSA Cycles

The four steps of the PDSA cycle should be repeated over and over to produce continual learning and improvement. A conceptual diagram ${ }^{36}$ suggesting the results from a repetition of PDCA cycles (which is a small variation on a PDSA cycle) is shown in Fig. 2 below:

As the PDSA/PDCA cycles themselves are continuously repeated and evolve, the resulting Quality outcomes (physical and/or mental) increase. The Real World process improvements and physical outcome improvements can optionally be consolidated and standardized. Externally observable improvements in Quality may not however always appear in the smooth linear manner Fig. 2 suggests. The externally observable improvements in Quality may sometimes appear (at least to outsiders) to come in unexpected jumps or leaps, as they did in the case of the BHC ibuprofen process.

The repetition of PDSA cycles suggested by Fig. 2 is, of course, really a general logical method for producing human guided and human accelerated evolution!! The PDSA and "Continuous Improvement" methods are adaptable to an incredibly wide variety of Real World processes. Such "Continuous Improvement" methods have already in fact, as seen above, been successfully implemented in the Real World by large numbers of organizations, in many industries, all over the World.

\section{Green Chemistry now?}

This author has spent the years following the events at Celanese as a chemical/pharmaceutical patent attorney, regularly working with inventors and state-of-the art chemistry and inventions from a wide variety of fields of chemistry, pharmaceuticals, and nanotechnology. The author has been intimately involved in due diligence activities related to funding for research activities, and involved in mergers and acquisitions. This author was intimately involved in a litigation resulting from a university professor's mis-appropriation, into his own private company, of a new (and subsequently FDA approved) drug that was actually invented by lower level scientists in the professor's university laboratories. The variety of inventions, legal matters, and business considerations one deals with as an IP/Business attorney is very challenging and has a wider scope than the technical matters I dealt with while working in the lab.

36 This diagram was copied from a Wikipedia article on the PDCA cycle available at https://en.wikipedia. org/wiki/PDCA, wherein the diagram is attributed to Johannes Vietze, who authorized its copying and use. 
These days, one can regularly see advertisements from major chemical/pharmaceutical companies, technology companies, car companies, etc., publicizing and promoting their new products and their efforts to improve their products and services in terms of quality, health, safety, and environmental issues. I have been loosely aware of the considerable and continuing growth of the Green Chemistry concepts, and "Movement."

During a slow period in my IP and business law practice in June 2012, I attended the 16th Annual Green Chemistry \& Engineering Conference in Washington D.C. The "theme" of the Conference was "Innovation, Jobs, Sustainability - The Role of Green Chemistry." The "Welcome" statement in the Conference Program stated that the Conference theme "reflects our belief that green chemistry and engineering hold the key to a sustainable future and can play a vital role in reinvigorating the global economy." I was very encouraged by that "theme."

I was also pleased with major portions of what I saw and experienced at the Green Chemistry Conference. Three or four hundred scientists from academia, industry, and government were in voluntary attendance, many giving technical presentations on their individualized approaches and/or solutions to a very wide variety of Green Chemical problems. Some major industrial companies and scientific organizations, public, private, educational, and governmental, were voluntary participants and/or sponsors. Much of that seemed to me to be as I hoped it might be. It made me proud and happy to think that I had something to do with the beginning of what I encountered.

But some other things I encountered at the 2012 Green Chemistry Conference troubled me. After multiple presentations, audience questions seemed to have a complaining tone, along the lines of "Management (or the government granting agency) doesn't take me seriously. I don't have enough support. How can I convince management and/or outsiders that this is really a worthwhile activity deserving of their support?"

Private discussions with several industrial attendees produced private complaints about strong negative impacts of EPA regulations on their research efforts and their downstream businesses. A private discussion with an upper level ACS official involved in organizing the Green Chemistry Conference produced a quiet complaint that some major industrial groups were only giving "token" support to Green Chemistry.

I attended a conference session on "Social Science Perspectives on Green Chemistry." An academic speaker from a prominent business school reported, clearly approvingly, significant evidence of a growing "collective identity" sub-movement within the Green Chemistry "Movement." When the presentation was over, I asked a question, namely what was the benefit of a "collective identity" sub-movement within Green Chemistry "movement"? Although the speaker's response went on for quite a while, and I have a Ph.D. in the sciences, and a Law degree, and practical experience in both fields, I literally couldn't understand the answer I received.

I then listened to a presentation by a senior academic/environmentalist "activist," advocating what she called the "Precautionary Principal," which (based on subsequent examination of her public writings on the Web) involved the following:

We must redesign our chemicals policy to be proactive, to favor erring on the side of precaution when there is uncertainty, and to making precaution the default position where there are missing data and conflicting results which prevent clear conclusions.... Implementing the precautionary approach requires immediately adopting three additional concrete strategies: 1 . shifting the burden of proof of safety onto the manufacturers of chemical products and processes; 2. activating a policy of "no data, no market", which means that chemicals lacking hazard data about their effects on 
human health and the environment cannot enter the marketplace; and 3. promoting the development of safer alternatives and substitutes.

While listening to the activist speaker's presentation, I had concerns about potentially strong legal side-effects of "shifting the burden of proof" (a legal concept). Negligence law in the US routinely imposes legal liability for failures to take reasonable precautions against foreseeable harms to others, but doesn't impose legal liability for unforeseeable harms. How does one address unforeseeable harms and risks? The burden of proving that foreseeable harm occurred has almost always been placed on the plaintiff, not the defendant, for many good reasons that are discussed in first year law student's "Torts" classes. I was concerned that the "activist" speaker's proposed legal scheme would make chemical industry (and maybe even the individual people working there) "guilty until proven innocent," even for unforeseeable future harms, including those resulting from research work, which inherently focuses on the exploration of the unknown and unpredictable.

After the "activist" speaker's talk, a speaker from a chemical manufacturer's group spoke, and took an opposing view, but didn't make some of the counter-arguments I would have raised. At the end of the industrial representative's talk, the "activist" speaker rose and loudly asked the industrial speaker derisive, emotional questions that were far more offensive than substantive.

At a break in the session, in the hall, I approached the "activist" speaker hoping for a private, rational conversation. I started to express my concerns, but within less than a minute, the "activist" speaker began very loudly, angrily, and repeatedly denouncing me personally (even though she had never previously known of me) as a corrupt and incompetent industry lawyer/stooge!! Her denunciations became so loud and angry that the people inside the presentation room, where the session had resumed, came out and pointedly shut the door.

I might have expected similar events if I had walked into an "Occupy" rally, but I certainly didn't expect such a reaction at a meeting of the American Chemical Society. After the meeting, concerned, I did some literature searching and found additional things that very much concerned me.

For example, in 2005, Professors Woodhouse and Breyman of the Science and Technology Studies Office of Rensselaer Polytechnic Institute published an article entitled "Green Chemistry as a Social Movement?" (Woodhouse and Breyman 2005). Professors Woodhouse and Breyman discussed and praised the BHC ibuprofen process invention, but had first started their paper with a question:

Might environmentally responsible technological innovation ever be led by technoscientists working within mainstream corporate, governmental, and university institutions?

Sadly, Woodhouse and Breyman's answer was no! Woodhouse and Breyman openly and explicitly advocated politically co-opting and coercing "Green" scientists to support "Progressive" and/or "Environmentalist" political causes. The concluding sentences of the Woodhouse/Breyman article read as follows:

But blindly relying on business executives and their techno-scientific employees and consultants to serve public purposes is what brought about the twentieth century's brown chemistry....Thus green chemistry may be too important to be left to those with technical training, even though they have started to move in very promising 
directions....It may be time for participants in the broader environmental movement to begin working with relevant experts to propose credible tax incentives, regulations, and mandates; forster public debate; and begin to use the state's legitimate coercive role to reshape innovation in line with public purposes - but to do so a good deal more deftly than some of the governmental steering of techno-science in the past century.

This author certainly has very serious concerns with the ignorance and arrogance of the Woodhouse/Breyman statements, and any proposed uses of "the state's legitimate coercive role to reshape innovation in line with public purposes." This author certainly doubts the Real World ability of far off academics, politicians and government regulators to coerce companies and scientists "a good deal more deftly than some of the governmental steering of techno-science in the past century."

This author is also very concerned that at least some speakers at the 2012 Green Chemistry conference were (consciously or unconsciously) pursuing the WoodhouseBreyman "politicization" strategy. This author will reserve his many more detailed objections and responses to Woodhouse and Breyman and their followers for other times and places, but notes the following.

Deming had serious issues with many American management practices, but he also had serious concerns about Government's role and ability to "regulate" industry (see Deming, 1982, 2000 at p. 302):

...in our industrial beginnings our standards were written by only two men. The maker and the user alone were concerned, and perhaps their only exchange was the oldest of specifications, 'Like the last one.' Government obviously has the right to set standards for the goods it buys. It is an interested party, and should be an active and watchful one.

There are trends, plans, and proposals currently under way, however, that would make standardization wholly or mainly a function of government, and I am opposed to them. I do not want my talented, capable, and sincere friends in the Federal agencies in Washington to write the industrial standards of the country. Too much is at stake.

If you control an industry's standards, you control that industry lock, stock, and ledger. On the day that standards become a governmental function and responsibility, as is now being threatened, the government will take a very long step toward the control of American industry.

In such a setup, governmental personnel will decide when and what standards should be developed and what the provisions of the standards should be. That method is inflexible. It does not permit the single manufacturer to depart from a standard in order to develop a specialized and useful business.

Standards made under such conditions tend to become limitations, controls, and restrictive procedures. They reduce consumer choice. No government planner knows enough to write the standards for the rest of American industry and all the American people.

As I understand Deming's other teachings, Deming didn't believe that far-off government politicians, planners, regulators, or academics could possibly hope to even know about, let alone deal effectively with, the infinity of constantly-changing and non-linear 
local technical and human complexities that are so critically important to solving local or specialized problems, in the present, or especially in the future, as is crucially necessary to actually produce genuinely good Quality, out in the Real World.

Near the end of the "Zen and the Art", Pirsig said the following:

I think if we are going to reform the world, and make it a better place to live in, the way to do it is not to talk about relationships of a political nature, which are inevitably dualistic, full of subjects and objects and their relationship to one another; or with programs full of things for other people to do. I think that kind of approach starts at the end and presumes the end is the beginning. Programs of a political nature are important end products of social quality that can be effective only if the underlying structure of social values is right. The social values are right only if the individual values are right. The place to improve the world is first in one's own heart and head and hands, and then work outward from there. Other people can talk about how to expand the destiny of mankind. I just want to talk about how to fix a motorcycle. I think what I have to say has more lasting value.

This author certainly believes that Woodhouse and Breymen and their followers are "guilty" of a political approach that "is full of things for other people to do," and "starts at the end and presumes the end is the beginning." They are also guilty of attempting to manage and/or lead "without knowing what to do."

If managers of chemical/pharmaceutical corporations regularly encounter tactics and emotional/political reactions like those I encountered at the 2012 Green Chemistry conference, I certainly understand why some modern advocates of "Green Chemistry" are not getting the respect and funding they desire.

Another anecdote from this author's experiences seems relevant. This author has a friend, ${ }^{37}$ Ms. Lynn Hill of Blowing Rock North Carolina, who obtained an Ivy League degree in Urban Planning several decades ago. After graduation Lynn went to India for several months to work with Mother Teresa, now a Nobel Peace Prize winner, and posthumous Catholic Saint. Lynn says that she asked Mother Teresa, "How is it that you've managed to accomplish such incredible things in your life?" Lynn says that Mother Teresa simply replied: "I focus on solving the problems that are before me every day."

I hope that what I encountered in 2012 was an aberration, but continue to fear it was not. While finishing this manuscript, I checked the "Technical Sessions" program for ACS's upcoming 21st Annual Green Chemistry \& Engineering Conference, scheduled for June 2017. One of the major conference sessions was entitled, "Green Chemistry = Social and Environmental Justice; Theory and Practice." I was greatly alarmed by this organized and blatantly one-sided and politicized attempt to equate "Green Chemistry" with the politics of "Social and Environmental Justice." I was also greatly alarmed by ACS's apparent support for such obvious politicization. ${ }^{38}$

With the election of Donald Trump and a Republican Congress in the US in 2016, and the "BREXIT" election results in Great Britain, the political winds have obviously changed radically. If the politicization I encountered is not an aberration, but a growing trend, as one of the 2012 conference academic speakers seemed to have evidence of, then "Green Chemistry" is going to encounter serious difficulties in the future. Might this be a

37 Ms. Hill and this author often disagree about politics, but remain friends nevertheless.

38 After this manuscript had been under review for some months, I checked the final program for the June 2017 Green Chemistry conference, and was happy to no longer find a "Social and Environmental Justice" session title. 
good time to abandon attempts to politicize Green Chemistry, and return toward a philosophy and goal of simply improving science, technology and Quality, with a politicly agnostic goal of simultaneously improving the Economy and Environment and the lives of everyone?

\section{Green Chemistry in the future?}

The economic, political and cultural crises of the 1960s and 1970s forced re-thinking by many people, including industrial scientists and their managers, in the 1980s. Part of that re-thinking was the efforts of commodity chemical companies to try to diversify into fine chemicals and pharmaceuticals. Another part of the re-thinking in industry was the "Quality" philosophy and teachings of W. Edwards Deming. I note that offshoots of the Deming problem solving techniques, in the form of "Six Sigma" and "Lean Six Sigma" statistical techniques, have been and still are being widely used in US industry, and are even described and supported on the EPA web-site, which now actually speaks about "Lean Government." 39

Those concepts, and a deepening understanding of changing customer needs and market opportunities and Celanese's commercial technologies, and an economic and anti-waste culture including Deming's teachings, were important influences on the thinking process this author used when originally conceiving the BHC ibuprofen process in 1984, and were also part of the thinking process of the Celanese co-workers who further developed and commercialized the original BHC Ibuprofen concept. We inventors weren't trying to start a new social, scientific, or political "movement." We were trying to make new products for new customers, via new technical processes that would be as technically superior, economically efficient and as waste free as possible. Our minds were "prepared" well enough by the company's culture and Deming's teachings to look for and then find and capitalize on a confluence of totally unpredictable economic and technical opportunities. We fully recognized that environmental improvements would result from our success, but we didn't have the luxury or goal of viewing environmental issues as our only task or focus. This author is confident that other early industrial "Green Chemical" inventors likely had similar influences and purposes.

In the 1990s, many concepts of "Green Chemistry" became more explicitly formalized, publicized, recognized, and elaborated by additional organizations, including Congress, the EPA, Chemical Engineering Magazine, academics such as Professor Barry Trost and Professor Roger Sheldon, the American Chemical Society, and many others, all of which evolutionary efforts this author applauds. Importantly, the concept that "Green Chemistry is Good Business" has now been more completely recognized in many more parts of industry, where Green Chemistry inevitably has to be implemented in any capitalist society. Some of Deming's teachings about management, and Real World applications of science and statistics have been adopted for the long run, but many of Deming's teachings about the importance of human factors such as psychology and "leadership" have too often been ignored or honored by their breach.

On balance, the growth and positive results produced by the Green Chemistry programs seems welcome. EPA is to be commended for promoting the voluntary Green Chemistry program. Industry and Academics certainly deserve credit and applause as well.

39 See the EPA website at http://www.epa.gov/lean/environment/methods/sixsigma.htm. 
But the BIG remaining question is not about the past, or anyone's genuine desire for progress, but rather how to go about producing Real World progress in the future? This author strongly hopes that the progress that has been achieved so far will not be spoiled in the future by adversarial political and/or "coercive" relationships between industry, academia, and government.

\section{Luke, use the Quality Force!!}

Who can possibly forget the Star Wars movies, wherein Yoda and/or Obie-Wan Kenobi so often yelled "Luke, Use the Force!"? "The Force" bestowed great power, which could be used for either good or evil. The "Dark Side of the Force" corrupted its users and produced fear and evil. But the "Good Side of the Force" could be used to perform acts of great heroism, to save humanity from the evil Empire. Real life history shows that Science, Chemistry, and Engineering can indeed have great "Force", both for good or for evil, and/ or many shades of grey in-between, depending on how that Force is actually used.

This author believes that concepts of "Quality," whether from Deming, Pirsig, movies, real religions, or from deep within each of us as individuals, can help lead and guide scientists and engineers and people from other disciplines, both as individuals and in groups, through an infinite complexity of good, bad, and grey choices toward a better future, even if it often leads there via totally unforeseeable paths. Quality as a goal can unite, rather than divide or coerce, people of widely varying backgrounds, training, and political persuasions. Then Quality scientific, statistical and management techniques, as taught by genuine leaders such as Deming, can actually guide both academics, managers and employees as to what they actually need to DO to produce "better" Quality in the future.

Woodhouse and Breyman did pose an important initial question: "Might environmentally responsible technological innovation ever be led by techno-scientists working within mainstream corporate, governmental, and university institutions?" Woodhouse and Breyman didn't seem to think so. But a better answer to the Woodhouse/Breyman question depends on what we really mean by the word "lead."

Clearly, in modern technological societies as they exist now, no new industrial or chemical process can be successfully developed and commercialized without the ultimate support and approval of both corporate managements (small or large), and by governments. But is support and approval by the "Empire" really the same thing as "leadership"?

Deming rejected "management by objective" or "visible figures alone," and challenged corporate managers to "lead" by creating an environment that allows their employees to be secure enough so that they can focus their attention on their customer's needs and desires, and the details of their own specific work processes, and improving those processes and products. Some corporate managers have done that, and are still leading their organizations in those directions. Some corporate managers have come to recognize that "Green Chemistry is Good Business". Unfortunately, too many managers haven't done those things, perhaps in order to cling to their own personal power and/or money?

Some in government and/or the EPA have "led by example," by supporting voluntary collaborations between scientists, managers, and government, such as the EPA and ACS Green Chemistry Programs. However, far too many of our managers/lawyers/politicians/ regulators continue to cling to legalized forms of "Management by Objective," routinely using fear and/or legal coercions, in an attempt to force other people to produce "good"? 
A study of history (especially legal history) shows that coercive approaches often not only fail to produce "good," but they often make things worse. Such legal/political/corporate "Management by Objective" probably fails because it does almost nothing to help the people being "led" to know what they actually should do to make things better. Unfortunately, not enough people at any level seem to know how to act in ways that actually improve both our individual lives and society, both now and in the future. Perhaps those are some of the reasons why we seem to find ourselves (at least "collectively") "Still in A Crisis"?

What can each of us, individually and/or in groups, actually do? Just stating a general lofty goal (including a Green Chemical goal) doesn't tell anybody much about what they need to do in the future.

Corporate managers (and government officials) can forego attempts to directly manipulate inherently unpredictable final outcomes, and instead adopt Quality principals to allow their employees to focus on their customers and improving their sub-processes. In return the Managers learn crucial local information useful to improve their particular products and services, and even discover new desirable products designed to meet constantly changing customer needs. If they really do that (rather than focusing on constant financial manipulations and/or "incentives") they can earn loyalty and continuing business from their customers, while also minimizing cost and waste, and so earn a fair profit.

Academics can teach their students their specific subject matter, as well as general concepts of "Excellence" and "Quality," and lead by example, rather than focusing on coercive political/legal approaches. If they teach and exemplify "Quality" concepts to their students, those students will hopefully learn to mimic and then use those "Quality" concepts in their own later life-paths, whatever those life-paths are. The students who do pursue Chemistry will easily see and understand Green Chemistry as a worthy goal, but will also learn how to identify what they each need to do in a very complex and unpredictable world.

Green Chemists and Engineers, and their team-members from other disciplines can, by considering "Quality," and by better focusing on the projects, processes and products they are working on every day, while also keeping an eye open to the changing needs and desires of their customers and the outside world, genuinely lead others toward a better, cleaner, and high Quality Greener future.

Robert Pirsig believed in a very personalized approach to identifying and producing "Quality". "The real cycle you're working on is a cycle called yourself." Nobody else has to grant an individual permission to work on improving themselves, their values and attitudes, and their focus and attention on what they are actually doing. Strive to bring a "Zen-like" focus to improving yourself, your own processes, and the things you produce every day. If you really do that, and you actually discover a new high quality invention, you'll have a much better chance of convincing your co-workers, corporate managers, customers, and/or the government and/or regulators to give you the support and permission you'll need in order to get a new Greener invention out of the lab, and out into the Real World.

Mark A. Murphy Ph.D., J.D. lives near Atlanta Georgia, and hopes to continue his career leading by example, somewhere at the interfaces of science, business, and law.

Open Access This article is distributed under the terms of the Creative Commons Attribution 4.0 International License (http://creativecommons.org/licenses/by/4.0/), which permits unrestricted use, distribution, and reproduction in any medium, provided you give appropriate credit to the original author(s) and the source, provide a link to the Creative Commons license, and indicate if changes were made. 


\section{References}

Anastas, P.T., Warner, J.C.: Green Chemistry Theory and Practice. Oxford University Press, New York (1998)

Anastas, P.T., Beach, E.S.: "Changing the Course of Chemistry," Chapter 1. In: "In Green Chemistry Education," Anastas, P.T. ACS Symposium Series, Washington DC 2009, Available at http://pubs.acs. org. doi:10.1021/bk-2009-1011.ch001

Baddely et al.: J. Chem. Soc. 4943-4945 (1956)

Cann, M.C., Connelly, M.E.: "The BHC Company Synthesis of Ibuprofen, a Greener Synthesis of Ibuprofen Which Creates Less Waste and Fewer Byproducts", chapter from "Real World Cases in Green Chemistry", pp. 19-24. American Chemical Society, Washington DC (2000)

Cornils, B., Herrmann, W.A., Rasch, M.: Otto Roelen, pioneer in industrial homogeneous catalysis. Angew. Chem. Int. Ed. Engl. 33(21), 2144-2163 (1994). doi:10.1002/anie.199421441

Davenport, K.G., Hilton, C.B.: Process for producing $N$-acyl-hydroxy Aromatic Amines, US Patent 4,524,217 issued June 18, 1985, and related US Patents 4,560,789, and 4,973,752

Deming, W.E.: Out of the crisis. First MIT Press Edition, 2000, originally published in 1982

Dennett, D.C.: Darwin's dangerous idea-evolution and the meanings of life. Simon and Shuster Paperbacks, New York (1995)

Eckert, M., Fleischmann, G., Jira, R., Bolt, H.M., Golka, K.: “Acetaldehyde”, Ulmann's Encyclopedia of Industrial Chemistry, vol. I, pp. 192-207. Wiley-VCH Verlag GmbH \& Co KGaA, Weinheim (2012)

Elango, V., Murphy, M.A., Smith, B.L., Davenport K.G., Mott, G.N., Zey, E.G., Moss, G.L.: "Method for Producing Ibuprofen," US Patent 4,981,995, granted January 1, 1991, claiming priority to an application filed March 20, 1987: also first published as EP 0284310(A1) published September 28, 1988

Evans, D., Osborn, J.A., Wilkinson, G.: Hydroformylation of alkenes by use of rhodium complex catalyst. J. Chem. Soc. 33(21), 3133-3142 (1994). doi:10.1039/J19680003133

Gabor, A.: The Man Who Discovered Quality: How W. Edwards Deming Brought the Quality Revolution to America. Times Books/Random House, New York (1990)

Gluckman, P.: Everyday Heroes of the Quality Movement; From Taylor to Deming, the Journey to Productivity. Dorset House Publishers, New York (1993)

Heck, R.F., Breslow, D.S.: J. Am. Chem. Soc. 83, 4023 (1961)

Hendricks, J.D., Mott, G.N.: Method for producing Ibuprofen. US Patent No. 5,166,418 issued Nov. 24, 1992, claiming priority to an application filed June 4, 1991

House, H.O.: Modern Synthetic Reactions, 2nd edn. W. A. Benjamin, San Francisco (1972)

Hoffstadter, D.R.: Gödel, Escher, Bach; An Eternal Golden Braid, A Metaphorical Fugue on Minds and Machines in the Spirit of Lewis Carrol, 1979. Basic Books Inc, 25th Anniversary Edition (1999)

Imyanitov, N.S., Rudkovskij, D.M.: Hydrogenation and hydroformylation in the presence of Co, Rh, and Ir carbonyls. Neftekhimiya (Rus) 3(2), 198-200 (1963)

Japanese Patent Kokai No. SHO 55 [1980]-27147

Japanese KoKai Patent No. SHO 59(1984)-95239, published June 1 (1984)

Johnston, V.J., Chen, L., Kimmich, B.F., Chapman, J.T., Zink, J.H.: US Patent No. 7,863,489 issued January 04, 2011, and assigned to Celanese International Corporation

Jones, J.H.: The cativa process for the manufacture of acetic acid. Platin. Met. Rev. 44(3), 94-105 (2000)

LookChem Website Article "Carbonylation of Methanol to Acetic Acid" at http://www.lookchem.com/ Chempedia/Chemical-Technology/Organic-Chemical-Technology/7550.html

Larkins, T.R., Polichnowski, S.W., Tustin, G.C., Young, D.A.: PCT Patent Application WO 82/01704 published May 27, 1982, assigned to Eastman Chemical Co

Lewis, A.H.: US Patent 2,833,825 (1958)

Lindley, D.D., Curtis, T.A., Ryan, T.R., de la Garza, E.M., Hilton, C.B., Kenesson, T.M.: Process for the production of 4'-isobutylacetophenone. US Patent 5,068,448 issued November 26, 1991, claiming priority to December 04, 1989, and assigned to Hoechst Celanese Corporation

Linthorst, J.A.: An overview: origins and development of green chemistry. Found. Chem. 12, 55-68 (2010). doi:10.1007/s10698-009-9079-4

Murphy, M.A., Smith, B.L., Torrence, G.P., Aguilo, A.: Iodide and acetate promotion of carbonylation of methanol to acetic acid, model and catalytic studies. J. Organomet. Chem. 303, 257-272 (1986)

Murphy et al.: US Patent 4,873,378 and US Patent 4,873,379 (October 10, 1989, claiming priority to Dec 15, 1987), and US Patent 4,935,554

Murphy, M.A., Czarney, M.R.: Purification of hydroxyphenyl alkanes. US Patent 5,202,505 issued April 13, 1993, claiming priority to March 24, 1992 
Murphy, M.A., Kvakovszky, G., Fritch, J.R.: UV light stabilizing, antioxidant, and colorant compounds. PCT Patent Application WO 93/15063 published Aug 05, 1993, claiming priority to Feb 03, 1992, eventually issued as US Patent 5,438,142

Mlodinow, L.: The Drunkard's Walk: How Randomness Rules Our Lives. Random House, New York (2008)

Nicholson, J.S., Adams, S.S.: Phenyl Propionic acids. US Patents 3,385,886 and 3,385,887 granted May 28, 1968, claiming priority to Jan 22, 1962

Paulik, F.E., Hershman, A, Know, W.R., Roth, J.F.: US Patent 3,769,329 issued October 30, 1973, assigned to Monsanto

Petersen, D.H., Murray, H.C.: J. Am. Chem. Soc. 71, 1871-1872 (1952)

Pirsig, R.M.: Zen and the art of motorcycle maintenance-an inquiry into values. First published by William Morrow in 1974, republished as a Bantam Edition in 1975, and a New Age Edition in September 1981 (used for reference purposed in this article)

Poliakoff, M.: A new father figure? TCE: The Chemical Engineer, 866 (2013)

Poliakoff, M., Licence, P.: Green Chemistry. Nature 450(6), 810-812 (2007)

Reinhard, J.: Acetaldehyde from ethylene-A retrospective on the discovery of the Wacker process. Angew. Chem. Int. Ed. 48, 9034-9037 (2009). doi:10.1002/anie.200903992

Roth, J.F.: The production of acetic acid-Rhodium catalyzed carbonylation of methanol. Platin. Met. Rev. 19(1), 12-14 (1975)

Sheldon, R.A.: Organic synthesis-Past, present, and future. Chem. Ind. 7, 903-906 (1992)

Sheldon, R.A., Arends, I., Hanefeld, U.: "Green Chemistry and Catalysis", Section 1.8, p. 23. Wiley-VCH Verlag GmbH, Weinheim (2007)

Sheldon, R.: Introduction to Green Chemistry, organic synthesis, and pharmaceuticals, Chapter 1. In: Dunn, P.J., Wells, A.S., Willams, M.T. (eds.), From "Green Chemistry in the Pharmaceutical Industry" (pp. 1-20). Wiley-VCH Verlag GmbH \& Co, Weinheim. ISBN 978-3-527-32418-7 (2010)

Simons, et al.: J. Am. Chem. Soc. 62, 485-486 (1940)

Smith, B.L., Torrence, G.P., Murphy, M.A., Aguilo, A.: The rhodium-catalyzed methanol carbonylation to acetic acid at low water concentrations: the effect of iodide and acetate on catalyst activity and stability. J. Mol. Catal. 39, 115-136 (1987)

Smith, B.L., Torrence, G.P., Aguilo, A., Alder, J.: Methanol carbonylation process. US Patent 5,001,259, issued 1991, claiming priority to 03 May 1984

Stille, J.K.: Asymmetric hydroformylation via polymer supported chiral catalysts. In: Robert, L. (ed.) Volume 22 of the "Catalysis of Organic Reactions" Series. Augustine, Marcel Dekker Inc, New York (1985)

Taleb, N.N.: The Black Swan-The Impact of the Highly Improbable, 1st ed, 2007, 2nd ed 2010. Random House, New York

Trost, B.M.: The atom economy- a search for synthetic efficiency. Science 254(5037), 1471-1477 (1991)

Vicari, R., Murphy, M.A.: Process for preparing improved polyarylates. US Patent 5,274,069 issued December 28, 1993, claiming priority to September 29, 1992

Wagner, F.S.: Acetic acid. In: Grayson, M. (ed.) Kirk-Othmer Encyclopedia of Chemical Technology, 3rd edn. Wiley, New York (1978)

Woodhouse, E.J., Breyman, S.: Green chemistry as a social movement? Sci. Technol. Hum. Values 30(2), 199-222 (2005)

Zey, E.G., Shockley, T.H., Ryan, D.A., Moss, G.L.: US Patent 5,151,551, issued September 29, 1992, priority claimed to September 06, 1990, and assigned to Hoechst Celanese Corporation

Zoeller, J.R., Agreda, V.H., Cook, S.L., Lafferty, N.L., Polichnowski, S.W., Pond, D.M.: Eastman chemical company acetic anhydride process. Catal. Today 13, 73-91 (1992)

Zoeller, J.R.: Eastman chemical company's 'Chemicals from Coal' program: the first quarter century. Catal. Today 140, 118-126 (2009) 